\title{
Booming with Speed: High-Speed Rail and Regional Green Innovation
}

\author{
Zixuan Zhu $(\mathbb{D}$, Xiaoyan Lin, and Hao Yang \\ Beijing Jiaotong University, Beijing 100044, China \\ Correspondence should be addressed to Hao Yang; hermanyang@bjtu.edu.cn
}

Received 20 October 2021; Accepted 13 December 2021; Published 29 December 2021

Academic Editor: Zhixiang Fang

Copyright (C) 2021 Zixuan Zhu et al. This is an open access article distributed under the Creative Commons Attribution License, which permits unrestricted use, distribution, and reproduction in any medium, provided the original work is properly cited.

Exploiting China's high-speed rail (HSR) as a quasi-natural experiment, we examine the relationship between the HSR connection and green innovation. The opening of HSR can promote green innovation by facilitating the flow of innovation factors. Using the multiperiod difference-in-differences (DID) model, we find that the regional green innovation performance significantly becomes better following the opening of HSR in the local city. Moreover, in examining the specific mechanisms at work, we find evidence that HSR stimulates green patents through increased labor mobility and research capital mobility. Further analyses show that the facilitating effect of HSR is heterogeneous among cities. Our paper sheds new light on the effects of HSR on social welfare in the case of sustainable economy.

\section{Introduction}

As one of the major technological innovations in the history of railway transportation, high-speed rail (HSR) has not only generated an unprecedented shrinkage of time and space [1] but also made a profound impact on the regional economy [2-4]. The mechanisms of HSR's effect on economic development have been richly studied, including network connectivity and spatial accessibility improvement [5], market expansion effect [6], industrial structure upgrading [7], industry agglomeration [8], technology spillovers (W. [9], production efficiency improvement [10], spatial equity improvement [11], and innovation [12].

However, most existing studies concerning HSR's impact are exclusively focused on one perspective, the economy. Comprehensive study on HSR's effect by integrating both economic development and environmental sustainability into an analytical framework is conducive and critical. Green innovation, which refers to a form of technological innovation aimed at reducing environmental pollution, is its intersection [13] and closely associated with geography [14]. Although China is the second largest economy, the longterm neglect of green innovation has resulted in a series of severe environmental issues and undermined its potential for economic growth [15]. While some cities in China have already attempted to implement green innovation activities, there are still clear regional disparities in green innovation performance [16].

To fill the gap in the existing literature and improve our understanding of green innovation, we exploit the HSR connection as a quasi-natural experiment to study its relationship with green innovation. This paper aims to answer three questions: Can HSR promote green innovation? Is the mobility of innovation factors a critical channel for verifying HSR's influence on green innovation? Are there any heterogeneities in terms of HSR's effect, and why?

HSR can widen the range of products available to consumers and make firms face much stronger competition [17]. In a fiercer competition environment, firms may choose to carry out green innovation activities to improve their core competitiveness, because these activities can reduce the cost of pollution prevention and control [18], obtain government tax breaks or subsidies in green innovation aspects [13], establish a better social image for their stakeholders [19], or increase the market shares or charge a premium price on customers who are more sensitive to 
environmental issues [20]. As Beneito [21] argues, the more competitive the environment firms evolve in, the more likely the generation of innovations is.

Meanwhile, with the production resources reallocation and transportation costs reduction caused by HSR services, enterprises may adjust their choices of firm locations [22-24]. On the one hand, the reselection of location may result in spatial agglomeration of firms [10], enhancing the knowledge and technology spillovers and the synergies between enterprises [8]. Considering the success of green innovation mainly depends on whether the organization can absorb external knowledge and transform it into internal skills [25], we argue that the HSR service can help enterprises improve the efficiency of green innovation $R \& D$ by exposing them to a larger-scale knowledge pool. HSR can also reduce variable trade costs and search costs due to more efficient buyer-supplier relationships [26], thus increasing firms' real profits and encouraging them to increase the R\&D investment in green innovation. On the other hand, facing the relocation of enterprises, local government officials tend to set stricter environmental regulations on enterprises as an environmental entry threshold, especially under the pressure of China's environmental target responsibility system. (For example, the government of Dongguan in Guangdong province issued the "Negative List of Environmental Entry for Construction Projects in Dongguan (2017)" on November 20, 2017, which lists the industries, processes, products, and development activities that are prohibited from access, to promote local green development.) This action may force enterprises to develop new green technologies in order to move into the region or to avoid heavy fines for environmental damage [27]. Overall, we propose our main hypothesis that HSR can positively influence regional green innovation.

We further hypothesize that HSR can promote green innovation through two potential mechanisms: the mobility of labor and the mobility of research capital. According to the resource-based theory, the innovation resources are important prerequisites for the enterprise to sustain a competitive advantage [28] or an effective green innovation strategy [29]. However, the double externality problem that green innovation produces positive spillovers in both the innovation and diffusion phase reduces the incentives for firms to invest in green innovation R\&D [30]. When innovation resources such as high-quality workforce or research capital are in shortage or have low output efficiency, firms will prioritize $R \& D$ projects which can generate a rapid return and allocate more resources to them [31, 32], for that environmental innovation has a lower return than nonenvironmental one in the short run [13]. When innovation resources are abundant, firms are allowed to have higher autonomy in selecting projects and are able to focus on green innovation [18]. HSR can broaden enhancement of cities' possibility of obtaining various innovation factors.

From the perspective of the workforce, once connected to the passenger-dedicated HSR network, more labor is free to move within the HSR range [1], especially the high-quality workforce with higher innovation abilities and professional skills [33]. HSR is conducive to the optimization of the spatial distribution of innovators and their matching efficiency with enterprises [34]. It can also prompt the exchange of ideas and accelerates knowledge spillovers and knowledge diffusion through face-to-face interactions, which cannot be effectively replaced by remote virtual communications in innovation production $[35,36]$.

From the perspective of research capital, its relationship with innovation has been richly studied in academia (e.g., $[37,38])$. It is largely undisputed that capital markets do not function in a space-neutral way [39-41]. Geographical locations limit the flow and substitution of financial resources due to their influence on the spatial diffusion of information about target companies [42] and on the size of the transaction cost and the monitoring cost [43]. By compressing the spatial-temporal distances between cities and strengthening the flexibility of face-to-face communication between investment institutions and enterprises, HSR can lessen the degree of information asymmetry and reduce the transaction cost, which is conducive to research capital to layout in longdistance cities with HSR and stimulates innovation activity [44]. Moreover, HSR can greatly improve the firm's profitability [45], allowing firms to allocate more capital into green innovation activity.

Exploiting the plausible randomness in the order of cities' connection to the HSR network, we begin our analysis with multiperiod difference-in-differences (DID) by employing panel data of 285 prefecture-level cities from 2005 to 2018 and estimate the impact of the HSR connection on green innovation with several city-level characteristics controlled as well as city and year fixed effects. Our empirical results show evidence that HSR is particularly beneficial to regional green innovation performance and that the effect is persistent over time. After a city is connected to the HSR network, the number of green utility model patent applications or granted and the number of green invention patent applications or granted will experience an average increase of $160,150,188$, and 46.5 annually.

Then, considering labor and research capital are the two main inputs in research and development (R\&D) activity, we assume and examine two plausible channels through which the HSR connection could affect the regional green innovation, namely, the labor mobility and the research capital mobility. Based on the gravity model, we construct two models to evaluate the two kinds of mobility between city pairs, as we detail in Section 2.3.3. The estimation result shows that the labor mobility and the research capital mobility are critical transmission paths for HSR to affect green innovation.

We further explore the cross-sectional heterogeneity of our main results from the perspective of various city characteristics. We find that HSR connection can contribute to green innovation more in the eastern and western regions, the Yangtze River Delta, and the Chengdu-Chongqing economic zone, cities with higher levels of development, and cities which attach more importance to local green development and practice more green activities.

We demonstrate the robustness of our results (1) with the parallel trend assumption test and (2) the placebo test, (3) by instrumenting the HSR connection with historical 
railways interacted with the number of cities connected to the HSR network in each province each year and with the interaction of the relief degree of the land surface (RDLS) and the year dummy variables, respectively, and (4) using the number of HSR stations and the HSR lines as the alternative explanatory variables. We also include the regional temperature as an indicator of the natural environment in our regression, which make almost no impact on our estimates, verifying that this paper's conclusions are valid.

Our paper contributes to the literature in the following ways: First, it adds to the literature on green innovation and its influencing factors. There has been a vast amount of research conducted on general innovation (e.g., [46-48]), as well as probing its relationship with transportation infrastructure $[49,50]$. However, an integrated analysis considering elements of both environmental economics and innovation economics is still hard to find [30]. We aim to bring the gap by focusing on city-level evidence with further extension to green innovation, a topic placed at the borderline between these two different economic subdisciplines.

Meanwhile, among the limited existing literature focused on green innovation, most studies identify and analyze its influencing factors from the perspective of stakeholder theory and institutional theory $[51,52]$, the basic theory of natural resources which concentrates on internal company factors such as the internal absorption capacity and environmental leadership [53,54], or the external factors which mainly refer to the pressure of policy from government regulations $[55,56]$. However, despite a series of valuable research results, the existing literature tends to neglect the role transportation infrastructures play in affecting regional green innovation, or their mechanism analyses are too ambiguous, or their estimations are based on a small and relatively simple sample [57]. Different from these studies, we broaden the scope by exploring all prefectural level or above cities in China. We employ a unique setting where the transportation system exogenously changed, the introduction of HSR, and then probe its relationship with regional green innovation.

Second, our paper adds to the literature innovation factor input and green innovation. The previous literature (e.g., $[21,58,59])$ shows that financial resources and human resources are the important prerequisites of $\mathrm{R} \& \mathrm{D}$ activities and key factors to stimulate general innovation. To make a marginal contribution, we extend the analysis to green innovation by integrating HSR, the innovation factor flow, and regional green innovation into a unified framework.

Moreover, our paper modifies the existing measurement of innovation factor flow to a more accurate method to improve the robustness of the estimation results. Previous studies tend to choose relatively static variable when measuring the innovation factor input, such as the difference between resident population growth rate and natural population growth rate [7] or the number of human resources owned by the company [32], but neglect the dynamic spatial mobility of these innovation factors. Or, some studies only calculate the resource inflow in a region without considering its outflow in their gravity model [57], which may underestimate the negative effects of the loss of innovation factors due to the HSR connection. In addition, using log transformations of all covariates in the gravity equation may pose issues in the estimation as a large share of flows are zero [60]. Different from these studies, our paper sets the gravity equation in its multiplicative form, as Silva and Tenreyro [61] suggested, and calculates the net inflow of resources in a region based on the "reflux and diffusion theory" [62].

This paper proceeds as follows: Section 2 provides detailed institutional background and describes the data. Section 3 provides the baseline analysis and explores the underlying mechanisms. Section 4 presents the heterogeneity analysis, and Section 5 presents the robustness checks. Section 6 concludes and discusses the study.

\section{Institutional Background and Data}

2.1. Institutional Background of the HSR Network. The opening of the Qinhuangdao-Shenyang passenger-dedicated railway on October 16, 2003, is viewed as a mark launching China's railroad system into the era of HSR. In 2004, to free up the freight services in the overloading existing rail network and meet the growing travel demand, China's State Council approved the first national railway network planning proposal, the Medium and Long-Term Railway Network Plan (MLRNP), to construct a passenger-dedicated high-speed transport network structure with four horizontal and four vertical corridors as the backbone and link all major cities with bullet trains. The latest revised version of MLRNP published in 2016 sets the new target of expanding HSR to more than $30,000 \mathrm{~km}$ by 2020 and constructing the HSR network structure with eight horizontal and eight vertical corridors. By the end of 2020, the national railroad has reached $146,000 \mathrm{~km}$, including $38,000 \mathrm{~km}$ of $\mathrm{HSR}$, which is the longest in the world today [63]. Figure 1 from (Ato) $\mathrm{Xu}$ and Huang [64] shows China's HSR network expansion process in four phases from 2007 to 2030. From 2007 to 2015, the HSR network expanded rapidly and covered almost 2/3 of national land areas. During 2016-2020, the HSR network construction mainly concentrated in China's central and western regions. In 2021-2030, the HSR network is expected to be denser and further extended to the marginal areas of China, such as Bortala in Xinjiang.

2.2. Sample Selection and Data Sources. As engines of growth, cities play an important role in economic development. We construct annual panel data of 285 prefecture level and above cities in China and augment them with information about the HSR network expansion to investigate its impact on regional green innovation. (Due to the serious incompleteness or inconsistency of data, the authors eliminate some city samples in this study, including Sansha, Qamdo, Lhasa, Nagqu, Xigaze, Shannan, Nyingchi, Bijie, Tongren, Haidong, Turpan, Hami and Hong Kong, Macao, and Taiwan.) In view of the staggering expansion of China's HSR since 2008, the research period of this paper is 2005-2018. It should be noted that although the Qinhuangdao-Shenyang railway operating since October 2003 is viewed as China's first HSR and considering all the variables 


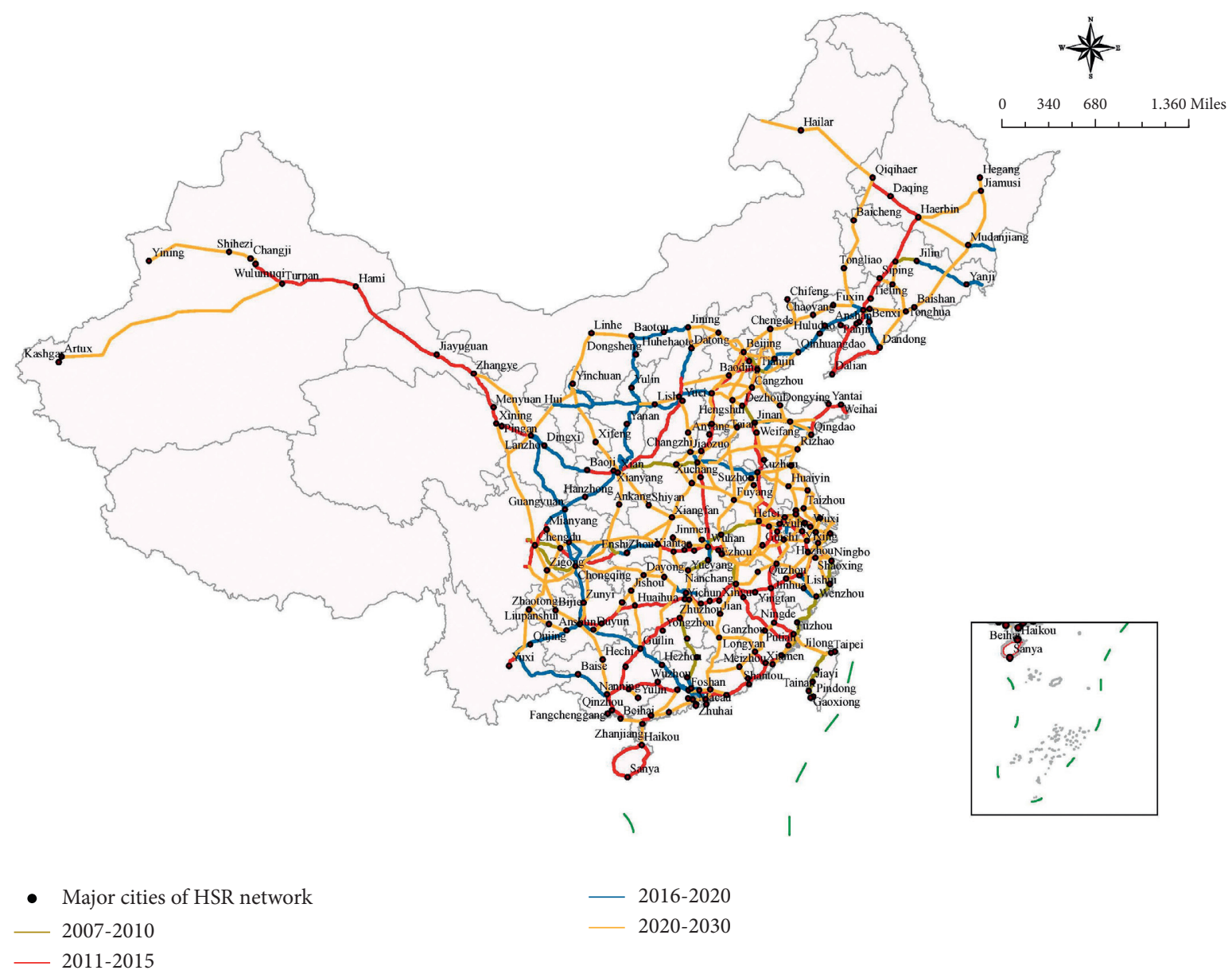

FIGURE 1: Development process of China's HSR network in periods over 2007-2030. Note: this map is from (Ato) Xu and Huang [64].

in our estimation models are lagged for one year, we take 2004 as the starting point for data collection and 2005 as the start of the study due to data unavailability of several variables in 2002 and 2003.

We manually collect HSR data from the China Railway Yearbooks, the China Railway Corporation website, and the National Railway Administration, where detailed information about HSR lines and stations can be obtained. Green innovation data are obtained from the State Intellectual Property Office of PR China (SIPO) based on the "IPC Green Inventory" classification. City-level control variables such as GDP and population are mainly obtained from China City Statistical Yearbooks and China Regional Statistical Yearbooks. The average house price data are from the China Real Estate Information website. The geographic distance between the source and the destination city is calculated according to each city's longitude and latitude. In response to some cities' missing data, this paper supplements these values by using linear interpolation. To control the influence of the outliers, we winsorize all continuous variables at $1 \%$ and $99 \%$, respectively. Table 1 presents detailed definitions of all variables employed in the regressions, as discussed in detail in Section 2.3. Table 2 presents the summary statistics of these variables for the full sample.

\subsection{Variable Construction}

2.3.1. HSR Data. In this study, the introduction of HSR is used as an exogenous shock to regional green innovation. According to the definition given by the International Union of Railways (UIC) in 2021, HSR lines refer to new lines designed for speeds above $250 \mathrm{~km} / \mathrm{h}$ and upgraded existing lines for up to 200 or even $220 \mathrm{~km} / \mathrm{h}$ [65]. In this paper, we set the core explanatory variable $\mathrm{HSR}_{i, t}$ to indicate whether city $i$ in year $t$ was connected to the HSR network. If an HSR route was introduced in city $i$ in year $t$, $\mathrm{HSR}_{i, t}$ takes the value of 1 from year $t$ and onward and 0 , otherwise. Based on this, all cities can be divided into two types: HSR cities and non-HSR cities. Considering some cities may only have HSR "passing" rather than "stopping," those cities with HSR lines passing through but with no HSR stations are not taken as HSR cities. A city only became an HSR city when the city's first HSR line was opened and the HSR trains of this line had a stop in this city. Since many HSR lines were opened in the second half of the year and the impact of HSR opening on green innovation may not be visible in a short time, the dummy variable of HSR opening is treated with a lag of one period in the regression model in this paper. 
TABLE 1: Variable definition.

\begin{tabular}{|c|c|}
\hline Variable & Definition \\
\hline HSR & Indicator for being connected to the HSR network \\
\hline GI & Green innovation \\
\hline GUMA & Number of green utility model patent applications \\
\hline GIA & Number of green invention patent applications \\
\hline GUMG & Number of green utility model patents granted \\
\hline GIG & Number of green invention patents granted \\
\hline \multicolumn{2}{|c|}{ Construction of labor and research capital mobility } \\
\hline$M_{i j t}$ & The mobility of labor from city $j$ to city $i$ in year $t$ \\
\hline wage & City's average wage level \\
\hline$h p r$ & City's annual average house price \\
\hline$L$ & City's labor market size \\
\hline$L I$ & City's total amount of labor inflow \\
\hline$L O$ & City's total amount of research capital outflow \\
\hline NetL & City's net research capital inflow \\
\hline$D_{i j}$ & City's distance between city $i$ and city $j$ \\
\hline$C_{i j t}^{i j}$ & Mobility of research capital from city $j$ to city $i$ in year $t$ \\
\hline profit & City's total profits of industrial enterprises \\
\hline finexp & City's percentage of public finance expenditure to GDP \\
\hline$S C$ & City's government expenditure on science and technology \\
\hline$C I$ & City's total amount of research capital inflow \\
\hline $\mathrm{CO}$ & City's total amount of research capital outflow \\
\hline NetC & City's net research capital inflow \\
\hline \multicolumn{2}{|c|}{ Control variables } \\
\hline $\ln g d p$ & Logarithm of real GDP \\
\hline $\operatorname{lnpop}$ & Logarithm of population \\
\hline thirdpc & Output share of the tertiary industry in the whole economy \\
\hline lnfore & Logarithm of foreign capital utilized \\
\hline roadpc & Area of paved roads per capital \\
\hline buspc & Number of bus and trolley bus per ten thousand people \\
\hline lngre & Logarithm of the area of green land \\
\hline $\operatorname{lneduc}$ & Logarithm of government expenditure on education \\
\hline policy1 & Dummy variable of the introduction of the target responsibility system of environmental protection policy in 2006 \\
\hline policy2 2 & Dummy variable of the introduction of the outline of the national intellectual property strategy in 2008 \\
\hline policy3 & Dummy variable of the introduction of new environmental law in 2015 \\
\hline
\end{tabular}

Note: GUMA, GIA, GUMG, and GIG are the indicators of GI. Given that some variables related to the total amount of money, area, or population are highly skewed, we use the natural logarithm of these variables, including $\operatorname{lng} d p$, Inpop, Infore, lngre, and lneduc. HSR and all control variables are lagged by one year.

Panel A of Table 2 shows the number and the shares of cities connected to the HSR network to the full sample from 2005 to 2018. It is evident that the HSR network in China experienced a rapid expansion from 2008 to 2011 and from 2012 to 2015 . It has grown from only $2.11 \%$ of cities connected to the HSR in 2007 to $72.13 \%$ in 2017 , and by 2014 , more than half of cities in our estimation sample were connected to the HSR network.

2.3.2. Green Innovation. Green innovation (GI) is an effective tool to address the conflict between economic development and environmental protection. The literature has proved the patent to be a fairly reliable indicator to capture the region's innovation creation [66]. Following Du et al. [67]; Moshirian et al. [48]; Su and Moaniba [68]; and Yi et al. [69], this paper uses green patent as a measure of green innovation output.

According to the Chinese Patent Law, the types of patents in China can be divided into three: invention type, utility model type, and appearance design type. "Invention" refers to new technical schemes for new products, new methods, or technology improvements, which represents the core technical achievements; "utility model" refers to a new technical solution for product shape or structure; "appearance design" refers to product's new appearance or pattern. Following Fan [12], we select invention patents and utility model patents to better reflect the regional innovation levels in this paper.

The specific search methods for green patent data are as follows: first, we use the "IPC Green Inventory" launched by World Intellectual Property Organization (WIPO) in 2010 to screen patent information related to environment-friendly technologies. The topics of "IPC Green Inventory" mainly include energy conservation, waste management, alternative energy production, transportation, nuclear power generation, agriculture/forestry, and administrative, regulatory, or design aspects. Then, according to the selected IPC classification number, we retrieve the number of green patents applications and the number of green patents granted through the patent search and analysis system of SIPO. After dividing the green patent type into invention innovation and 
TABLE 2: Summary statistics of variables.

\begin{tabular}{|c|c|c|c|c|c|c|c|}
\hline \multicolumn{8}{|c|}{ Panel A: HSR connectedness over time } \\
\hline Year & $\begin{array}{l}\text { Cities connected to } \\
\text { HSR network }\end{array}$ & $\begin{array}{c}\text { \% connected to HSR } \\
\text { network }\end{array}$ & $N$ & Year & $\begin{array}{l}\text { Cities connected to } \\
\text { HSR network }\end{array}$ & $\begin{array}{c}\% \text { connected to HSR } \\
\text { network }\end{array}$ & $N$ \\
\hline 2005 & 6 & $2.11 \%$ & 285 & 2012 & 92 & $32.28 \%$ & 285 \\
\hline 2006 & 6 & $2.11 \%$ & 285 & 2013 & 111 & $38.95 \%$ & 285 \\
\hline 2007 & 6 & $2.11 \%$ & 285 & 2014 & 149 & $52.28 \%$ & 285 \\
\hline 2008 & 15 & $5.26 \%$ & 285 & 2015 & 174 & $61.05 \%$ & 285 \\
\hline 2009 & 34 & $11.93 \%$ & 285 & 2016 & 183 & $64.21 \%$ & 285 \\
\hline 2010 & 55 & $19.30 \%$ & 285 & 2017 & 190 & $66.67 \%$ & 285 \\
\hline 2011 & 71 & $24.91 \%$ & 285 & 2018 & 203 & $71.23 \%$ & 285 \\
\hline \multicolumn{8}{|c|}{ Panel B: summary statistics of city-level characteristics } \\
\hline Variable & Mean & Standard deviation & Minimum & $p(25)$ & Median & $p(75)$ & Maximum \\
\hline HSR & 0.32 & 0.47 & 0.00 & 0.00 & 0.00 & 1.00 & 1.00 \\
\hline GUMA & 0.18 & 0.42 & 0.00 & 0.01 & 0.04 & 0.13 & 2.67 \\
\hline GIA & 0.19 & 0.53 & 0.00 & 0.01 & 0.02 & 0.10 & 3.53 \\
\hline GUMG & 0.16 & 0.38 & 0.00 & 0.01 & 0.03 & 0.11 & 2.43 \\
\hline GIG & 0.05 & 0.13 & 0.00 & 0.00 & 0.00 & 0.02 & 0.85 \\
\hline NetL & -0.04 & 1.67 & -3.13 & -0.95 & -0.34 & 0.39 & 8.34 \\
\hline NetC & 3.00 & 18.61 & -32.00 & -2.35 & -0.19 & 1.65 & 118.82 \\
\hline $\operatorname{lngdp}$ & 15.19 & 1.44 & 8.06 & 14.38 & 15.13 & 15.96 & 18.61 \\
\hline lnpop & 5.86 & 0.70 & 3.82 & 5.47 & 5.91 & 6.35 & 7.58 \\
\hline thirdpc & 0.44 & 0.11 & 0.09 & 0.36 & 0.43 & 0.51 & 0.98 \\
\hline lnfore & 9.52 & 2.07 & 0.00 & 8.41 & 9.65 & 10.93 & 16.36 \\
\hline roadpc & 10.57 & 6.25 & 0.69 & 6.00 & 9.45 & 13.48 & 59.49 \\
\hline buspc & 7.22 & 4.66 & 0.58 & 3.78 & 6.20 & 9.74 & 22.13 \\
\hline lngre & 8.04 & 1.10 & 4.69 & 7.36 & 7.94 & 8.66 & 11.43 \\
\hline lneduc & 12.39 & 1.02 & 8.50 & 11.67 & 12.44 & 13.13 & 14.78 \\
\hline
\end{tabular}

utility model innovation, this study uses four indicators (in thousand units) to measure green innovation: (1) the number of green invention patent applications (GIA), (2) the number of green invention patents granted (GIG), (3) the number of green utility model patent applications (GUMA), and (4) the number of green utility model patents granted (GUMG).

The summary statistics of four green patents are shown in Panel B of Table 2. Although the number of applications for green invention patents is higher than that for green utility model patents, the number of granted green invention patents is much lower, which is consistent with the fact that the examination and authorization process of green invention patents is more complex and stricter than that of green utility model patents and thus the novelty of invention patents is higher.

2.3.3. Mechanism Factor. Economic theory suggests that the mobility of factors is determined by a set of push and pull factors related to the source and destination city [70]. In this paper, we employ the gravity equation in its multiplicative form with both a pull factor and a push factor to assess the mobility of labor and research capital.

As to labor mobility, Borjas [71] and Karemera et al. [72] show that migration flows are negatively related to the income level of the source country. Cervero and $\mathrm{Wu}$ [73] point out that the low house prices in peripheral locations act as a pull factor in location choices of labor. Hunt [74] argues that labor mobility depends mainly on the wages that can be obtained and on the affordability of the housing. Using the multinomial logit model, So et al. [75] also have the same result that individuals make residential and job location choices by trading off wages and housing prices and a $10 \%$ increase in metropolitan housing costs reduces metropolitan residence by $3.4 \%$. Lewer and Van den Berg [76] and Murphy et al. [77] find that the larger the labor pool size in the source city and the destination city, the higher the labor flow rate. Following this literature, we use the sending city's and the receiving city's average wage levels, house prices, and labor market sizes as the gravity factors of labor mobility across cities follow the literature. The labor mobility is also restrained by migration costs that can be captured by the geographic distance between the source and destination city. Thus, the gravity model of labor mobility is set as follows:

$$
\begin{aligned}
M_{i j t} & =\left(\frac{\text { wage }_{i t}}{\text { wage }_{j t}}\right)^{\lambda_{1}} *\left(\frac{h p r_{j t}}{h p r_{i t}}\right)^{\lambda_{2}} * \frac{L_{i}^{\alpha_{1}} * L_{j}^{\alpha_{2}}}{D_{i j}^{\varphi}} \\
\mathrm{LI}_{i t} & =\sum_{j}^{284} M_{i j t}, \\
\mathrm{LO}_{i t} & =\sum_{j}^{284} M_{j i t}, \\
\mathrm{Net}_{i t} & =\mathrm{LI}_{i t}-\mathrm{LO}_{i t},
\end{aligned}
$$

where $M_{i j t}$ is the mobility of labor from city $j$ to city $i$ in year $t$; wage is the city's average wage level; $h p r$ is the annual average house prices; $L$ is the measure of the city's labor market size; $D_{i j}$ calculates the distance between city $i$ and 
city $j$; and $\varphi$ denotes the distance attenuation index between regions. Considering that distance is becoming less of a barrier to migration as regional transportation becomes increasingly convenient, in this paper, $\varphi$ takes the value of 1 [70]. $\lambda_{1}$ and $\lambda_{2}$ represent the weight coefficients of the two indexes; $\alpha_{1}$ and $\alpha_{2}$ are gravitational parameters of labor size. Following von Bertalanffy [78], we take the weight of the main index $\left(\alpha_{1}, \alpha_{2}\right)$ and the weight of the secondary index $\left(\lambda_{1}, \lambda_{2}\right)$ all equal to $0.5 . \mathrm{LI}_{i t}$ represents the total amount of labor attracted by city $i$ in year $t$ by summing up $M_{i j t}$ at the regional level. $\mathrm{LO}_{i t}$ represents the total amount of labor outflow from city $i$ to all other cities in year $t$ by summing up $M_{j i t}$ at the regional level. Therefore, $\operatorname{Net} L_{i t}$ is the net labor inflow of city $i$ in year $t$.

As to capital mobility, we use the total profits of industrial enterprises, the percentage of public finance expenditure to GDP, and the expenditure on science and technology in the source and destination city, as well as the geographic distance, as the gravity factors of research capital flows $[79,80]$. It should be noted that the percentage of public finance expenditure measures the degree of government intervention in the market. The larger the percentage, the higher the degree of intervention and the lower the degree of market liberalization, which is inversely related to the city's attractiveness for capital. The gravity model of labor mobility is as follows:

$$
\begin{aligned}
C_{i j t}= & \left(\frac{\mid \text { profit }_{i t} \mid}{\mid \text { profit }_{j t} \mid}\right)^{\lambda_{3}} *\left(\frac{{\text { fin } \exp _{j t}}_{\text {fin } \exp _{i t}}}{\lambda_{4}} * \frac{\mathrm{SC}_{i}^{\alpha_{3}} * \mathrm{SC}_{j}^{\alpha_{4}}}{D_{i j}^{\varphi}}\right. \\
& * \frac{\max \left(\text { profit }_{i t}, 0\right)}{\text { profit }_{i t}}, \\
\mathrm{CI}_{i t}= & \sum_{j}^{284} C_{i j t}, \\
\mathrm{CO}_{i t}= & \sum_{j}^{284} C_{j i t}, \\
\mathrm{Net}_{i t}= & \mathrm{CI}_{i t}-\mathrm{CO}_{i t},
\end{aligned}
$$

where $C_{i j t}$ is the mobility of research capital from city $j$ to city $i$ in year $t$; profit is the total profits of the city's industrial enterprises; finexp is the percentage of public finance expenditure to GDP; SC is the government expenditure on science and technology; $\varphi$ takes the value of 1 ; and $\alpha_{3}, \alpha_{4}, \lambda_{3}$, and $\lambda_{4}$ are all equal to 0.5 . Considering a small number of cities have a negative total profit of industrial enterprises in certain years, this paper assumes that these cities cannot attract capital in that year, so that the capital inflow $C_{i j t}$ will be $0 . \mathrm{CI}_{i t}$ represents the total capital attracted by city $i$ in year $t$ by summing up $C_{i j t}$ at the regional level. $\mathrm{CO}_{i t}$ represents the total capital outflow from city $i$ to all other cities in year $t$ by summing up $C_{j i t}$ at the regional level. Therefore, $\operatorname{Net} C_{i t}$ is the net capital inflow of city $i$ in year $t$.
2.3.4. Control Variables. We control for a multitude of city-level attributes that may affect regional green innovation performance in our model. We use the logarithm of gross domestic product (lngdp) and the logarithm of the population (lnpop) in each city each year to control the local socioeconomic environment, referring to Kuang et al. [45]. The industrial structure is controlled by using the output share of the tertiary industry in the whole economy (thirdpc), referring to Wang et al. [7]. Transportation infrastructure level is controlled by using the area of paved roads per capital (in square meter) (road $p c$ ) and the number of bus and trolley buses per ten thousand people (in units) (buspc), referring to X. Zhang et al. [81]. The degree of market openness is controlled by using the logarithm of the amount of foreign capital utilized (in ten thousand dollars) (lnfore), referring to Yang et al. [49]. The basic condition of the environment is controlled by using the logarithm of the area of green land (in hectare) (lngre), referring to Zheng and Kahn [82]. The basic level of innovative human capital plays an important role in regional innovation which is controlled by using the logarithm of government expenditure on education (lnedu), referring to Moser and Voena [83]. Three major policies related to green patent incentives or environmental performance assessment are also selected as control variables, all of which are dummy ones: the Target Responsibility System of Environmental Protection, implemented at the start of the 11th Five-Year Plan period in 2006 (policy1) (This is an environmental policy which for the first time quantitatively defined the emission requirement of pollutants. It links the environmental indicators, such as chemical oxygen demand (COD) and total emissions of sulfur dioxide $\left(\mathrm{SO}_{2}\right)$, the two major pollutants, as the binding indicators to the performance assessment of government officials, marking the shift of China's environmental regulation from "soft restriction" to "hard restriction."); the Outline of the National Intellectual Property Strategy in 2008, emphasizing the importance of creating, utilizing, protecting, and administering intellectual property (policy2); and the introduction of new "Environmental Law" in 2015 (policy3). policyi $(i=1,2,3)$ takes one from the year a given policy started to enact.

\section{Empirical Strategy and Analysis}

In this section, we describe our time-varying DID empirical framework in detail and present the estimation results of HSR's effect on the regional green innovation performance. Then, to better understand the process through which HSR impacts the regional green innovation output, we test two potential mechanisms at work: labor mobility and research capital mobility.

3.1. HSR and Regional Green Innovation. We use a multiperiod DID model with city and year fixed effects to test our main hypothesis that regional green innovation will benefit from its connection to the HSR network. It should be noted 
that, before choosing our baseline model form, we firstly use the DID model from pooled OLS regressions controlling for year and city fixed effects and then employ the random-effect panel estimation and fixed-effect panel estimation, respectively. The Hausman test significantly rejects the null hypothesis, suggesting that there is correlation between the regressors and the unobserved individual effects. Therefore, we choose to use the fixed-effects estimator. We estimate our baseline regression in the following form:

$$
\mathrm{GI}_{i t}=\alpha+\beta_{0} * \mathrm{HSR}_{i, t-1}+\gamma * X_{i, t-1}+u_{i}+v_{t}+\varepsilon_{i t},
$$

where $\mathrm{GI}_{i t}$ represents the green innovation output in city $i$ in year $t$, including four green patent measures (i.e., GIA, GIG, GUMA, and GUMG); $\mathrm{HSR}_{i, t-1}$ is the core explanatory variable in this model and indicates connection to the HSR network in city $i$ in year $t-1 ; X_{i, t-1}$ denotes a vector of oneyear lags of control variables, including $\operatorname{lng} d p$, lnpop, third $p c$, road $p c$, bus $p c, \ln$ fore, lngre, Inedu, policy1, policy2, and policy $3 ; u_{i}$ and $v_{t}$ are vectors of city fixed effects and year fixed effects, respectively; and $\varepsilon_{i t}$ is the random error term. The main coefficient of interest, $\beta$, captures the average change in regional green innovation output in response to regional HSR introduction. We expect $\beta$ to be significantly positive.

Meanwhile, to have a deeper understanding of the HSR time dynamic effects, we refer to the method used by Kong et al. [84] and modify equation (3) by replacing $\mathrm{HSR}_{i, t-1}$ with $\mathrm{HSR}_{i, t-2}, \mathrm{HSR}_{i, t-3}, \mathrm{HSR}_{i, t-4}$, and $\mathrm{HSR}_{i, t-5}$. Taking $\mathrm{HSR}_{i, t-2}$ as an example, it will take the value of 1 in the second year of HSR connection and onwards.

We report the estimated results of HSR's effect on regional green innovation in Table 3 , with column titles indicating the specific outcome variables. In Columns (1-4), the results show that the coefficients of HSR are all significantly positive at the $1 \%$ level, indicating that the HSR connection can promote regional green innovation which verifies our basic hypothesis in this paper. The results are also economically meaningful. Compared with non-HSR cities, the number of GUMA, the number of GIA, the number of GUMG, and the number of GIG will increase with an additional 160,188, 150, and 46.5 units on average per year in HSR cities. It makes sense that HSR's effect on the application number is higher than that on the granted number because not all green patents can pass the review procedure. Comparing utility model patents with invention patents, even that GIA is higher than GUMA, HSR's effect on GIG is significantly smaller than its effect on GUMG, possibly due to the much higher novelty of green invention patents and their stricter and more time-consuming review procedure.

Columns (5-8) of Table 3 show the estimation results of the time dynamics of HSR's effect. We can see that the coefficient estimates of $\mathrm{HSR}_{i, t-2}, \mathrm{HSR}_{i, t-3}, \mathrm{HSR}_{i, t-4}$, and $\mathrm{HSR}_{i, t-5}$ are all positive and pass the significance test at the $5 \%$ level or above (except for the coefficient of $\mathrm{HSR}_{i, t-2}$ on GUMA), indicating that instead of a one-time boost, the improvement on regional green innovation appears to persist for several years after HSR connection. In sum, the results in Table 3 suggest that regional green innovation performance can benefit from the connection to the HSR network, and such benefits appear to persist over time.

3.2. Mechanism Tests. To verify the potential two mechanism discussed in Section 1, we employ the classic three-step model [85] and use the labor mobility variable and the research capital mobility variable as the mediators to construct the mediating effect models, respectively. The models are as follows:

$$
\begin{aligned}
\operatorname{Net}_{i t} & =\alpha+\beta_{1} * \mathrm{HSR}_{i, t-1}+\gamma * X_{i, t-1}+u_{i}+v_{t}+\varepsilon_{i t}, \\
\mathrm{GI}_{i t} & =\alpha+\beta_{2} * \mathrm{HSR}_{i, t-1}+\lambda_{1} * \operatorname{Net} L_{i t}+\gamma * X_{i, t-1}+u_{i}+v_{t}+\varepsilon_{i t}, \\
\mathrm{Net}_{i t} & =\alpha+\beta_{3} * \mathrm{HSR}_{i, t-1}+\gamma * X_{i, t-1}+u_{i}+v_{t}+\varepsilon_{i t}, \\
\mathrm{GI}_{i t} & =\alpha+\beta_{4} * \mathrm{HSR}_{i, t-1}+\lambda_{2} * \operatorname{Net}_{i t}+\gamma * X_{i, t-1}+u_{i}+v_{t}+\varepsilon_{i t},
\end{aligned}
$$

where $\operatorname{Net} L_{i t}$ is the net labor inflow of city $i$ in year $t-1$ (outflow if $\operatorname{Net} L_{i t}<0$ ) and $\mathrm{Net} C_{i t}$ is the net capital inflow of city $i$ in year $t-1$ (outflow if $\mathrm{Net}_{i t}<0$ ).

In the three-step model, step 1 checks the relationship between green innovation and HSR. The model of step one is identical to baseline model (9), and the results are shown in Columns (1-4) of Table 3. Step 2 checks the relationship between HSR and the mediator variables, namely, the labor flow and the capital flow, as equations (4) and (6) show. $\beta_{1}$ and $\beta_{3}$ are expected to be significantly positive. Step 3 verifies the relationship between green innovation and HSR when these two mediators are separately controlled in the regression models, as equations (5) and (7) show. Specifically, if $\beta_{2}, \beta_{4}, \lambda_{1}$, and $\lambda_{2}$ are all significantly positive and $\beta_{2}$ and $\beta_{4}$ are significantly reduced, a significant mediation effect exists.

The estimation results of the mediation effects of the labor mobility and the research capital mobility are listed in Panel A and Panel B of Table 4, respectively. Column (1) of both panels show the results of step 2. The coefficients of HSR in Column (1) are significantly positive at the $1 \%$ level, showing that HSR can promote the mobility of labor and 
TABLE 3: HSR connection and regional green innovation.

\begin{tabular}{|c|c|c|c|c|c|c|c|c|}
\hline & $\begin{array}{c}(1) \\
\text { GUMA }\end{array}$ & $\begin{array}{c}(2) \\
\text { GIA }\end{array}$ & $\begin{array}{c}(3) \\
G U M G\end{array}$ & $\begin{array}{l}(4) \\
G I G\end{array}$ & $\begin{array}{c}(5) \\
\text { GUMA }\end{array}$ & $\begin{array}{c}(6) \\
\text { GIA }\end{array}$ & $\begin{array}{c}(7) \\
G U M G\end{array}$ & $\begin{array}{c}(8) \\
G I G\end{array}$ \\
\hline L.HSR & $\begin{array}{l}0.160^{* * *} \\
(0.0264)\end{array}$ & $\begin{array}{l}0.188^{* * *} \\
(0.0326) \\
\end{array}$ & $\begin{array}{l}0.150^{* * *} \\
(0.0244)\end{array}$ & $\begin{array}{c}0.0465^{* * *} \\
(0.00803)\end{array}$ & & & & \\
\hline L2.HSR & & & & & $\begin{array}{c}0.0787^{* * *} \\
(0.0199)\end{array}$ & $\begin{array}{c}0.0732^{* * *} \\
(0.0226)\end{array}$ & $\begin{array}{c}0.0698^{* * *} \\
(0.0157)\end{array}$ & $\begin{array}{l}0.0202^{* * *} \\
(0.00483)\end{array}$ \\
\hline L3 HSR & & & & & $\begin{array}{l}0.00902 \\
(0.0127)\end{array}$ & $\begin{array}{c}0.0378^{* *} \\
(0.0151)\end{array}$ & $\begin{array}{c}0.0336^{* *} \\
(0.0150) \\
\end{array}$ & $\begin{array}{l}0.0113^{* * *} \\
(0.00361)\end{array}$ \\
\hline L4.HSR & & & & & $\begin{array}{c}0.0755^{* * *} \\
(0.0165)\end{array}$ & $\begin{array}{c}0.0791^{* * *} \\
(0.0229) \\
\end{array}$ & $\begin{array}{c}0.0530^{* * *} \\
(0.0136)\end{array}$ & $\begin{array}{l}0.0188^{* * *} \\
(0.00431)\end{array}$ \\
\hline L5.HSR & & & & & $\begin{array}{c}0.299^{* * *} \\
(0.0453) \\
\end{array}$ & $\begin{array}{c}0.365^{* * *} \\
(0.0627) \\
\end{array}$ & $\begin{array}{l}0.251^{* * *} \\
(0.0376)\end{array}$ & $\begin{array}{c}0.0796^{* * *} \\
(0.0129) \\
\end{array}$ \\
\hline$L . \ln g d p$ & $\begin{array}{c}0.118^{* *} \\
(0.0575)\end{array}$ & $\begin{array}{c}0.117^{*} \\
(0.0620) \\
\end{array}$ & $\begin{array}{c}0.0961^{*} \\
(0.0504) \\
\end{array}$ & $\begin{array}{c}0.0192 \\
(0.0139) \\
\end{array}$ & $\begin{array}{c}0.137^{* *} \\
(0.0630) \\
\end{array}$ & $\begin{array}{c}0.137^{* *} \\
(0.0649) \\
\end{array}$ & $\begin{array}{c}0.112^{* *} \\
(0.0543) \\
\end{array}$ & $\begin{array}{l}0.0238^{*} \\
(0.0139) \\
\end{array}$ \\
\hline L.lnpop & $\begin{array}{c}0.196^{* * *} \\
(0.0571)\end{array}$ & $\begin{array}{c}0.246^{* * *} \\
(0.0769)\end{array}$ & $\begin{array}{l}0.182^{* * *} \\
(0.0550)\end{array}$ & $\begin{array}{c}0.0544^{* * *} \\
(0.0186)\end{array}$ & $\begin{array}{l}0.122^{* * *} \\
(0.0337)\end{array}$ & $\begin{array}{c}0.153^{* * *} \\
(0.0478)\end{array}$ & $\begin{array}{l}0.114^{* * *} \\
(0.0327)\end{array}$ & $\begin{array}{c}0.0319^{* * *} \\
(0.0104) \\
\end{array}$ \\
\hline L.thirdpc & $\begin{array}{l}0.268^{*} \\
(0.151) \\
\end{array}$ & $\begin{array}{c}0.281 \\
(0.196) \\
\end{array}$ & $\begin{array}{c}0.279^{* *} \\
(0.134) \\
\end{array}$ & $\begin{array}{c}0.0867^{*} \\
(0.0447) \\
\end{array}$ & $\begin{array}{c}0.175 \\
(0.159) \\
\end{array}$ & $\begin{array}{c}0.206 \\
(0.205) \\
\end{array}$ & $\begin{array}{c}0.198 \\
(0.140) \\
\end{array}$ & $\begin{array}{c}0.0709 \\
(0.0464) \\
\end{array}$ \\
\hline L.lnfore & $\begin{array}{c}-0.0175^{* *} \\
(0.00701)\end{array}$ & $\begin{array}{c}-0.0132 \\
(0.00826)\end{array}$ & $\begin{array}{c}-0.0159^{* *} \\
(0.00620)\end{array}$ & $\begin{array}{c}-0.00401^{* *} \\
(0.00189)\end{array}$ & $\begin{array}{c}-0.0147^{* *} \\
(0.00674)\end{array}$ & $\begin{array}{l}-0.00902 \\
(0.00774)\end{array}$ & $\begin{array}{c}-0.0135^{* *} \\
(0.00585)\end{array}$ & $\begin{array}{c}-0.00320^{*} \\
(0.00173)\end{array}$ \\
\hline L.roadpc & $\begin{array}{c}-0.000784 \\
(0.00297)\end{array}$ & $\begin{array}{c}0.000801 \\
(0.00354)\end{array}$ & $\begin{array}{l}-0.00140 \\
(0.00261)\end{array}$ & $\begin{array}{c}0.000128 \\
(0.000844)\end{array}$ & $\begin{array}{l}-0.00129 \\
(0.00278)\end{array}$ & $\begin{array}{c}0.0000422 \\
(0.00296)\end{array}$ & $\begin{array}{l}-0.00189 \\
(0.00232)\end{array}$ & $\begin{array}{c}-0.0000423 \\
(0.000712)\end{array}$ \\
\hline L.buspc & $\begin{array}{c}0.0113^{* *} \\
(0.00453) \\
\end{array}$ & $\begin{array}{c}0.0136^{* *} \\
(0.00551)\end{array}$ & $\begin{array}{c}0.00987^{* *} \\
(0.00398) \\
\end{array}$ & $\begin{array}{c}0.00314^{* * *} \\
(0.00118) \\
\end{array}$ & $\begin{array}{c}0.00767^{*} \\
(0.00401)\end{array}$ & $\begin{array}{c}0.0103^{* *} \\
(0.00482) \\
\end{array}$ & $\begin{array}{c}0.00676^{*} \\
(0.00348) \\
\end{array}$ & $\begin{array}{c}0.00220^{* *} \\
(0.000951) \\
\end{array}$ \\
\hline L.Ingre & $\begin{array}{l}-0.0207 \\
(0.0213)\end{array}$ & $\begin{array}{l}-0.0420 \\
(0.0279)\end{array}$ & $\begin{array}{l}-0.0141 \\
(0.0201)\end{array}$ & $\begin{array}{l}-0.00800 \\
(0.00701) \\
\end{array}$ & $\begin{array}{l}-0.0216 \\
(0.0263)\end{array}$ & $\begin{array}{l}-0.0510 \\
(0.0338)\end{array}$ & $\begin{array}{l}-0.0110 \\
(0.0250)\end{array}$ & $\begin{array}{l}-0.00897 \\
(0.00830)\end{array}$ \\
\hline L.lneduc & $\begin{array}{l}-0.0968 \\
(0.0646) \\
\end{array}$ & $\begin{array}{l}-0.0549 \\
(0.0747) \\
\end{array}$ & $\begin{array}{c}-0.100 \\
(0.0608) \\
\end{array}$ & $\begin{array}{l}-0.0109 \\
(0.0163) \\
\end{array}$ & $\begin{array}{l}-0.0619 \\
(0.0473) \\
\end{array}$ & $\begin{array}{l}-0.0112 \\
(0.0558) \\
\end{array}$ & $\begin{array}{l}-0.0680 \\
(0.0435) \\
\end{array}$ & $\begin{array}{c}-0.00157 \\
(0.0117) \\
\end{array}$ \\
\hline L.policy 1 & $\begin{array}{c}0.0194 \\
(0.0486) \\
\end{array}$ & $\begin{array}{c}-0.00327 \\
(0.0631) \\
\end{array}$ & $\begin{array}{c}0.0287 \\
(0.0455) \\
\end{array}$ & $\begin{array}{l}0.00203 \\
(0.0143) \\
\end{array}$ & $\begin{array}{c}0 \\
(.)\end{array}$ & $\begin{array}{c}0 \\
(.)\end{array}$ & $\begin{array}{c}0 \\
(.)\end{array}$ & $\begin{array}{l}0 \\
(.)\end{array}$ \\
\hline L.policy2 & $\begin{array}{c}0.191^{*} \\
(0.116)\end{array}$ & $\begin{array}{c}0.121 \\
(0.145) \\
\end{array}$ & $\begin{array}{c}0.197^{*} \\
(0.109)\end{array}$ & $\begin{array}{c}0.0326 \\
(0.0327) \\
\end{array}$ & $\begin{array}{c}0.113 \\
(0.0989) \\
\end{array}$ & $\begin{array}{l}0.0125 \\
(0.132) \\
\end{array}$ & $\begin{array}{c}0.125 \\
(0.0909) \\
\end{array}$ & $\begin{array}{c}0.0107 \\
(0.0299) \\
\end{array}$ \\
\hline L.policy3 & $\begin{array}{l}0.106^{* * *} \\
(0.0256)\end{array}$ & $\begin{array}{l}0.100^{* * *} \\
(0.0332)\end{array}$ & $\begin{array}{l}0.119^{* * *} \\
(0.0240) \\
\end{array}$ & $\begin{array}{c}0.0132^{*} \\
(0.00678) \\
\end{array}$ & $\begin{array}{c}0.0318 \\
(0.0267) \\
\end{array}$ & $\begin{array}{c}0.00984 \\
(0.0358) \\
\end{array}$ & $\begin{array}{l}0.0526^{* *} \\
(0.0244)\end{array}$ & $\begin{array}{l}-0.00793 \\
(0.00762) \\
\end{array}$ \\
\hline cons & $\begin{array}{l}-1.586 \\
(1.049) \\
\end{array}$ & $\begin{array}{l}-2.232 \\
(1.373) \\
\end{array}$ & $\begin{array}{l}-1.223 \\
(0.959) \\
\end{array}$ & $\begin{array}{l}-0.422 \\
(0.306) \\
\end{array}$ & $\begin{array}{c}-1.772^{*} \\
(0.939) \\
\end{array}$ & $\begin{array}{c}-2.393^{*} \\
(1.226) \\
\end{array}$ & $\begin{array}{c}-1.391^{*} \\
(0.829) \\
\end{array}$ & $\begin{array}{c}-0.450^{*} \\
(0.265) \\
\end{array}$ \\
\hline Year & Yes & Yes & Yes & Yes & Yes & Yes & Yes & Yes \\
\hline City & Yes & Yes & Yes & Yes & Yes & Yes & Yes & Yes \\
\hline $\mathrm{N}$ & 3923 & 3923 & 3923 & 3923 & 3361 & 3361 & 3361 & 3361 \\
\hline$R^{2}$ & 0.321 & 0.257 & 0.311 & 0.246 & 0.414 & 0.345 & 0.397 & 0.341 \\
\hline
\end{tabular}

Note: the estimation sample includes 285 prefecture level and above cities in China. The sample period is from 2005 to 2018. Dependent variables are indicated by column titles in italics. GUMA, GIA, GUMG, and GIG are the number of green utility model patent applications, the number of green invention patent applications, the number of green utility model patents granted, and the number of green invention patents granted. HSR and all control variables are controlled and lagged by one year in all regressions. All regressions include city fixed effects and year fixed effects. Robust standard errors in parentheses are clustered at the city level. The symbols ${ }^{* * *},{ }^{* *}$, and ${ }^{*}$ indicate significance at the $1 \%, 5 \%$, and $10 \%$ levels, respectively.

research capital. Columns (2-5) of both panels show the results of step 3. We can see that all the coefficients of Net $L$ are significantly positive at the $1 \%$ level and all the coefficients of NetC are significantly positive at the $10 \%$ level. Meanwhile, the coefficients of HSR in Table 4 are lower than the corresponding coefficients of HSR in Columns (1-4) of Table 3. The results indicate that boosting labor mobility and research capital mobility are two critical transmission paths for HSR to influence regional green innovation.

\section{Heterogeneity Analysis}

Many scholars have examined and proved that transportation infrastructure such as HSR has a heterogeneous impact on the economy or innovation activities among cities $[3,6,49]$. In this section, we thoroughly examine the different impacts of HSR connection on regional green innovation by conducting four heterogeneity analyses from the perspective of four economic zones, four urban 
TABLE 4: Mechanism test: labor flow and research capital flow.

\begin{tabular}{|c|c|c|c|c|c|}
\hline \multicolumn{6}{|c|}{ Panel A: labor flow } \\
\hline & $(1)$ & (2) & (3) & (4) & (5) \\
\hline & NetL & GUMA & GIA & GUMG & GIG \\
\hline & $0.140^{* * *}$ & $0.137^{* * *}$ & $0.159^{* * *}$ & $0.128^{* * *}$ & $0.0396^{* * *}$ \\
\hline L.HSR & $(0.0425)$ & $(0.0238)$ & $(0.0295)$ & $(0.0216)$ & $(0.00667)$ \\
\hline & & $0.167^{* * *}$ & $0.208^{* * *}$ & $0.155^{* * *}$ & $0.0493^{* * *}$ \\
\hline NetL & & $(0.0283)$ & $(0.0377)$ & $(0.0253)$ & $(0.00916)$ \\
\hline Controls & Yes & Yes & Yes & Yes & Yes \\
\hline Year & Yes & Yes & Yes & Yes & Yes \\
\hline City & Yes & Yes & Yes & Yes & Yes \\
\hline $\mathrm{N}$ & 3923 & 3923 & 3923 & 3923 & 3923 \\
\hline $\mathrm{r} 2$ & 0.0513 & 0.384 & 0.321 & 0.379 & 0.317 \\
\hline \multicolumn{6}{|c|}{ Panel B: research capital flow } \\
\hline \multirow{4}{*}{ L.HSR } & (1) & (2) & (3) & (4) & (5) \\
\hline & NetC & GUMA & GIA & GUMG & $G I G$ \\
\hline & $0.261^{* * *}$ & $0.156^{* * *}$ & $0.182^{* * *}$ & $0.144^{* * *}$ & $0.0449^{* * *}$ \\
\hline & $(0.0666)$ & $(0.0255)$ & $(0.0313)$ & $(0.0232)$ & $(0.00763)$ \\
\hline \multirow{2}{*}{$\mathrm{NetC}$} & & $0.0163^{*}$ & $0.0234^{*}$ & $0.0204^{*}$ & $0.00627^{*}$ \\
\hline & & $(0.00880)$ & $(0.0121)$ & $(0.0107)$ & $(0.00321)$ \\
\hline Controls & Yes & Yes & Yes & Yes & Yes \\
\hline Year & Yes & Yes & Yes & Yes & Yes \\
\hline City & Yes & Yes & Yes & Yes & Yes \\
\hline$N$ & 3923 & 3923 & 3923 & 3923 & 3923 \\
\hline $\mathrm{r} 2$ & 0.0471 & 0.325 & 0.261 & 0.317 & 0.252 \\
\hline
\end{tabular}

Note: Panel A shows the result of labor flow as the mechanism, and Panel B shows the result of taking research capital flow as the mechanism. These two variables are constructed by the gravity model. Column (1) in both panels shows the result of the second step in the classic three-step model [85], and Columns (2-5) show the result of the third step (the result of the first step is shown in Columns (1-4) of Table 3). HSR and all control variables are included and lagged by one year in all regressions. All regressions include city fixed effects and year fixed effects. Robust standard errors in parentheses are clustered at the city level. The symbols ${ }^{* * *},{ }^{* *}$, and ${ }^{*}$ indicate significance at the $1 \%, 5 \%$, and $10 \%$ levels, respectively.

agglomerations, different urban development levels, and different green awareness levels, respectively.

4.1. Four Economic Zones. Based on the traditional economic geography classification method, we begin our analysis by dividing the full sample into four economic zones: East, Central, West, and Northeast, as shown in Figure 2. The empirical results of the grouped regression are shown in Panel A of Table 5. It shows that the coefficient estimates of the core explanatory variable HSR pass the significance test at the $1 \%$ level in eastern cities and at least $5 \%$ level in western cities, which means that the eastern region and the western region can enjoy a greater increase in green innovation after HSR connection. However, the coefficients are not significant in central and east-northern cities. In addition, the average treatment effect of HSR in eastern cities on GUMA, GIG, and GUMG are more than that in western cities (the corresponding average impact is 240,224 , and 66.3 in eastern cities and 170, 146, and 53.6 in western cities), suggesting that the eastern region enjoys larger improvements in green innovation after HSR connection. The impact on GIA is almost the same in eastern and western regions. The relative sizes of impact among four kinds of patents are the same as our baseline regression results.

These findings are consistent with those of Fan [12], who argues that it is mainly because the eastern region has a good foundation for innovation and the western region has a highly inclined support policy such as Low Carbon Pilot Policy, while central and northeastern regions possess neither of these two advantages and their innovation environment is weak. Meanwhile, the previous literature points out that with local green environmental regulation tightening, firms that have difficulties in carrying out green innovation $R \& D$ and reducing the pollutant emissions in the short term may choose to relocate to the region where the mandates are less stringent to avoid the high pollution abatement costs and maximize their profits [86, 87]. Such migration may lead to the mixture of enterprises with strong green innovation ability and those with weak green innovation ability in inland areas, making it difficult for inland areas to benefit from good R\&D externalities and thus reducing their overall green innovation ability.

4.2. Four Urban Agglomerations. Urban agglomeration (UA) is one of the most important carriers for a country's economic development and incubators for innovation, where the exchange of capital, information, and labor within the UAs are more active than those outside [8], especially in China $[88,89]$. UAs and the transportation network have become China's core points of spatial planning and regional development in the 21 st century [81,90].

To test whether green innovation in cities in UAs can benefit more from the HSR connection, we select the panel data of cities from the four largest and most developed UAs in China: the Beijing-Tianjin-Hebei metropolitan region 


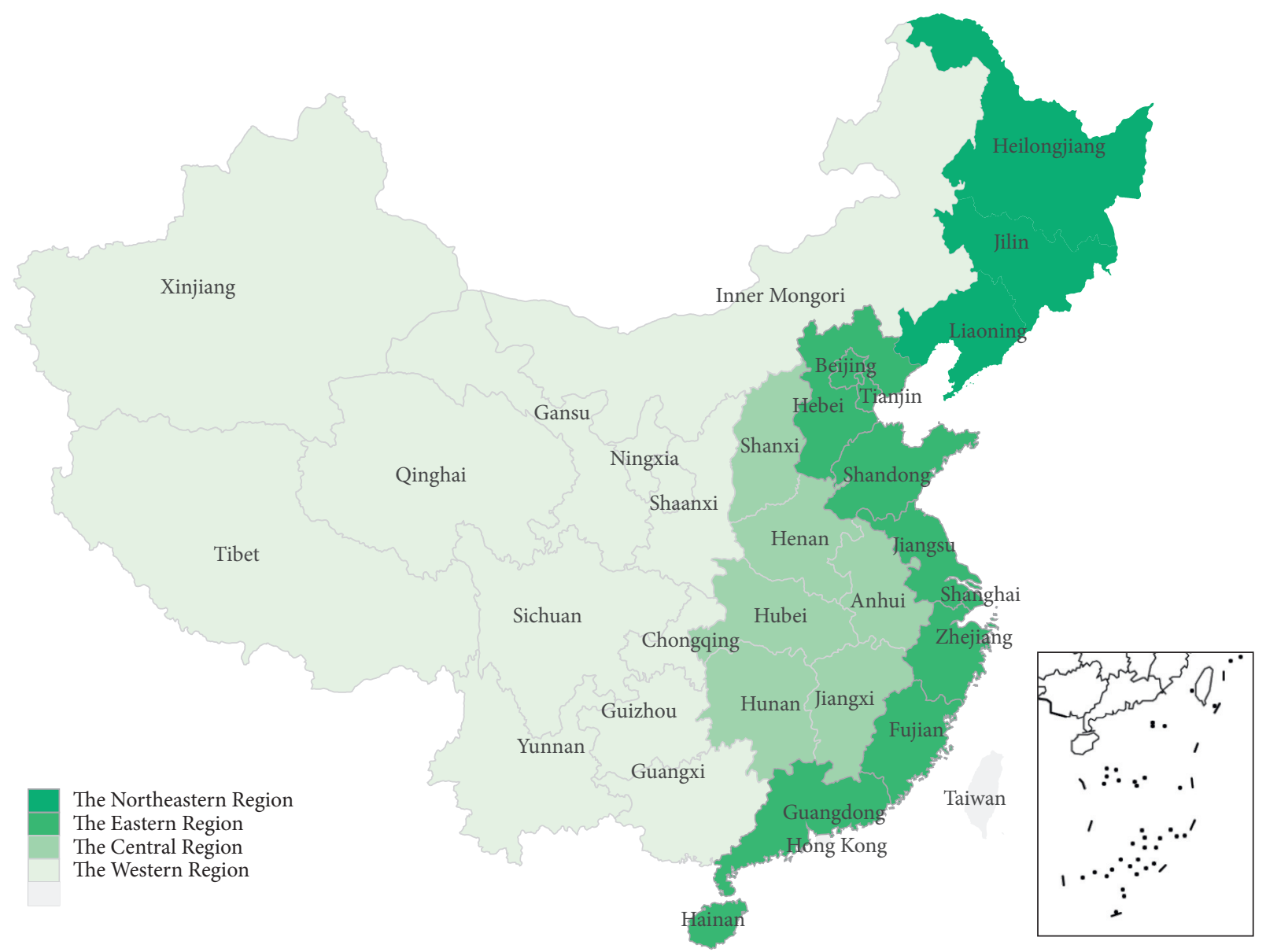

Figure 2: Four economic zones in China.

(BTH), the Yangtze River Delta (YRD), the Pearl River Delta (PRD), and the Chengdu-Chongqing economic zone (CY) spanning 2005-2018, which are located in the north, the east, the south, and the west of China and encompass 16 cities, 41 cities, 9 cities, and 16 cities, respectively. The location of the four UAs is shown in Figure 3.

The results of the grouped regression at the scale of the four UAs are shown in Panel B of Table 5. It shows that variations also exist between city clusters. The coefficients of HSR for cities in four groups are all positive but only significant in YRD and CY. The possible explanation is that the allocation efficiency of $\mathrm{R} \& \mathrm{D}$ resources in $\mathrm{BTH}$ is inferior [91] and the development of infrastructure provides a good physical environment for innovation activities in YRD, while the effect is not statistically significant in PRD [92]. For GUMA and GUMG, HSR connection can increase the amounts of each patent by 162 and 168 for cities in YRD per year on average and 392 and 352 for cities in CY per year on average, which means that cities in $\mathrm{CY}$ can benefit more from the HSR connection. Moreover, the estimates are greater than the baseline estimates of 160 for GUMA and 150 for GUMG, as shown in Columns (1) and (3) of Table 3. For invention patents, the application amount and the granted amount can increase to 222 and 52 on average for cities in YRD per year and 463 and 101 for cities in CY, which are all greater than the baseline results of 188 and 47 for full-sample cities. Therefore, compared to cities not in YRD and CY, cities in these two UAs can experience a more significant increase in green innovation performance after connection to the HSR network, proving that UAs play a more crucial role in establishing an innovative country.

4.3. Urban Development Level. The treatment effect of HSR also varies from city to city [93]. Following Hao et al. [94], who use the urban development index (UDI) constructed by Didi Company to evaluate the current urban livability development in China, we also use this index generously shared by Xu et al. [95] to explore HSR's heterogeneous impact on regional green innovation. This index is an overall evaluation of each city's current development level by adopting massive, microscopic data in the Didi platform. It contains four subindexes: economic development, social livelihood, cultural environment, and urban spatial efficiency. We rank our full-sample cities based on UDI and divide them equally into three groups: cities with high, medium, and low levels of UDI. We suppose that cities with a higher level of overall development can experience much increase on green innovation after the HSR connection.

The results of the grouped regression based on UDI are shown in Panel A of Table 6. The coefficients of HSR for cities in all three groups are positive but are not significant in 
TABLE 5: Heterogeneity analysis on economic zones and urban agglomerations.

\begin{tabular}{|c|c|c|c|c|c|c|c|c|}
\hline & \multicolumn{4}{|c|}{ Panel A: four economic zones } & \multicolumn{4}{|c|}{ Panel B: four urban agglomerations } \\
\hline & East & Center & West & Northeast & BTH & YRD & $\mathrm{CY}$ & PRD \\
\hline & \multicolumn{4}{|c|}{ GUMA } & \multicolumn{4}{|c|}{ GUMA } \\
\hline & (1) & $(2)$ & (3) & $(4)$ & (1) & (2) & (3) & $(4)$ \\
\hline & $0.240^{* * *}$ & 0.0138 & $0.170^{* *}$ & 0.0491 & 0.0387 & $0.162^{* *}$ & $0.392^{* *}$ & 0.108 \\
\hline L.HSR & $(0.0558)$ & $(0.0146)$ & $(0.0646)$ & $(0.0398)$ & $(0.0954)$ & $(0.0680)$ & $(0.140)$ & $(0.227)$ \\
\hline$R^{2}$ & 0.520 & 0.353 & 0.224 & 0.306 & 0.796 & 0.653 & 0.563 & 0.824 \\
\hline Test of group: coefficient difference & \multicolumn{4}{|c|}{ East vs. west } & \multicolumn{4}{|c|}{ YRD vs. CY } \\
\hline \multirow[t]{3}{*}{ Observed difference } & \multicolumn{4}{|c|}{0.198} & \multicolumn{4}{|c|}{$-0.230^{*}$} \\
\hline & \multicolumn{4}{|c|}{ GIA } & \multicolumn{4}{|c|}{ GIA } \\
\hline & $(5)$ & $(6)$ & $(7)$ & $(8)$ & $(5)$ & $(6)$ & $(7)$ & $(8)$ \\
\hline & $0.252^{* * *}$ & 0.00420 & $0.255^{* * *}$ & 0.0924 & -0.0632 & $0.222^{* *}$ & $0.463^{* * *}$ & 0.175 \\
\hline L.HSR & $(0.0674)$ & $(0.0298)$ & $(0.0788)$ & $(0.0753)$ & $(0.128)$ & $(0.0891)$ & $(0.149)$ & $(0.294)$ \\
\hline$R^{2}$ & 0.407 & 0.289 & 0.217 & 0.240 & 0.728 & 0.566 & 0.541 & 0.782 \\
\hline Test of group: coefficient difference & \multicolumn{4}{|c|}{ East vs. west } & \multicolumn{4}{|c|}{ YRD vs. CY } \\
\hline \multirow[t]{3}{*}{ Observed difference } & \multicolumn{4}{|c|}{-0.008} & \multicolumn{4}{|c|}{-0.241} \\
\hline & \multicolumn{4}{|c|}{ GUMG } & \multicolumn{4}{|c|}{ GUMG } \\
\hline & (9) & $(10)$ & $(11)$ & $(12)$ & (9) & $(10)$ & $(11)$ & $(12)$ \\
\hline & $0.224^{* * *}$ & 0.0183 & $0.146^{* *}$ & 0.0484 & 0.0214 & $0.168^{* * *}$ & $0.352^{* *}$ & 0.120 \\
\hline L.HSR & $(0.0506)$ & $(0.0131)$ & $(0.0582)$ & $(0.0366)$ & $(0.0971)$ & $(0.0610)$ & $(0.122)$ & $(0.182)$ \\
\hline$R^{2}$ & 0.502 & 0.356 & 0.210 & 0.298 & 0.788 & 0.640 & 0.562 & 0.823 \\
\hline Test of group: coefficient difference & \multirow{2}{*}{\multicolumn{4}{|c|}{$\begin{array}{c}\text { East vs. west } \\
0.074\end{array}$}} & \multicolumn{4}{|c|}{ YRD vs. CY } \\
\hline \multirow[t]{3}{*}{ Observed difference } & & & & & & & & \\
\hline & \multicolumn{4}{|c|}{ GIG } & \multicolumn{4}{|c|}{ GIG } \\
\hline & $(13)$ & $(14)$ & $(15)$ & $(16)$ & (13) & $(14)$ & $(15)$ & $(16)$ \\
\hline & $0.0663^{* * *}$ & 0.00740 & $0.0536^{* * *}$ & 0.0289 & 0.00520 & $0.0518^{* *}$ & $0.101^{* * *}$ & 0.0941 \\
\hline L.HSR & $(0.0161)$ & $(0.00589)$ & $(0.0190)$ & $(0.0208)$ & $(0.0176)$ & $(0.0196)$ & $(0.0325)$ & $(0.0608)$ \\
\hline$R^{2}$ & 0.390 & 0.259 & 0.184 & 0.263 & 0.731 & 0.533 & 0.527 & 0.780 \\
\hline Test of group: coefficient difference & \multicolumn{4}{|c|}{ East vs. west } & \multicolumn{4}{|c|}{ YRD vs. CY } \\
\hline Observed difference & \multicolumn{4}{|c|}{0.010} & \multicolumn{4}{|c|}{-0.049} \\
\hline Controls & Yes & Yes & Yes & Yes & Yes & Yes & Yes & Yes \\
\hline Year & Yes & Yes & Yes & Yes & Yes & Yes & Yes & Yes \\
\hline City & Yes & Yes & Yes & Yes & Yes & Yes & Yes & Yes \\
\hline $\mathrm{N}$ & 1177 & 1120 & 1150 & 476 & 224 & 640 & 256 & 144 \\
\hline
\end{tabular}

Note: in Panel A, cities in our estimation sample are divided into four groups based on the location of these cities (i.e., the east, the center, the west, and the northeast economic zones). In Panel B, cities in four urban agglomerations are selected as samples to test the heterogeneity of HSR's effect on regional green innovation (i.e., the BTH, the YRD, the CY, and the PRD). The test of coefficient difference between groups is carried out using the bootstrap method. The bootstrap number in this paper is set to bs (1000). HSR and all control variables are included and lagged by one year in all regressions. All regressions include city fixed effects and year fixed effects. Robust standard errors in parentheses are clustered at the city level. The symbols ${ }^{* * *},{ }^{* *}$ and ${ }^{*}$ indicate significance at the $1 \%, 5 \%$, and $10 \%$ levels, respectively.

the sample of cities with low UDI. In the sample of cities with medium UDI, the average treatment effects of HSR on no matter which indicators of green innovation are significantly positive at the $5 \%$ level or above. Cities with high development levels, of which the HSR coefficients are positive and significant at the $1 \%$ level for all four kinds of patents, enjoy a much greater increase in green innovation after HSR connection than those with medium development level. The average treatment effects of HSR on GUMA, GIA, GUMG, and GIG in cities with high UDI are 271, 318, 254, and 80.3, respectively, while the corresponding average effects are 47 , $64.1,43.9$, and 14.7 in cities with medium UDI. These results further indicate that the HSR connection has a more obvious effect in cities with higher development levels when improving green innovation performance.

4.4. Green Awareness Level. The rapid growth of public environmental awareness leads to increasing constraints on enterprises through customers' product selection rights, but it also gives a significant opportunity to firms to put in more efforts in green innovation to attract more customers or charge a premium price. Therefore, we argue that the green innovation performance can benefit more in cities with higher green awareness levels after the HSR connection.

In this paper, we use the "green sharing index" (GSI) as a proxy indicator of the awareness level of green development, a secondary index of the cultural environment in Didi's UDI. GSI is measured by three tertiary indexes: the proportion of car-pooling and hitchhiking to total orders on Didi application, the quantity proportion of new energy orders, and the milage proportion of new energy orders. Car-pooling, hitchhiking, and choosing to take a new energy vehicle are all voluntary behaviors of environmental protection and energy conservation, indicating how much local people attach importance to the concept of local green development and how much they practice. 


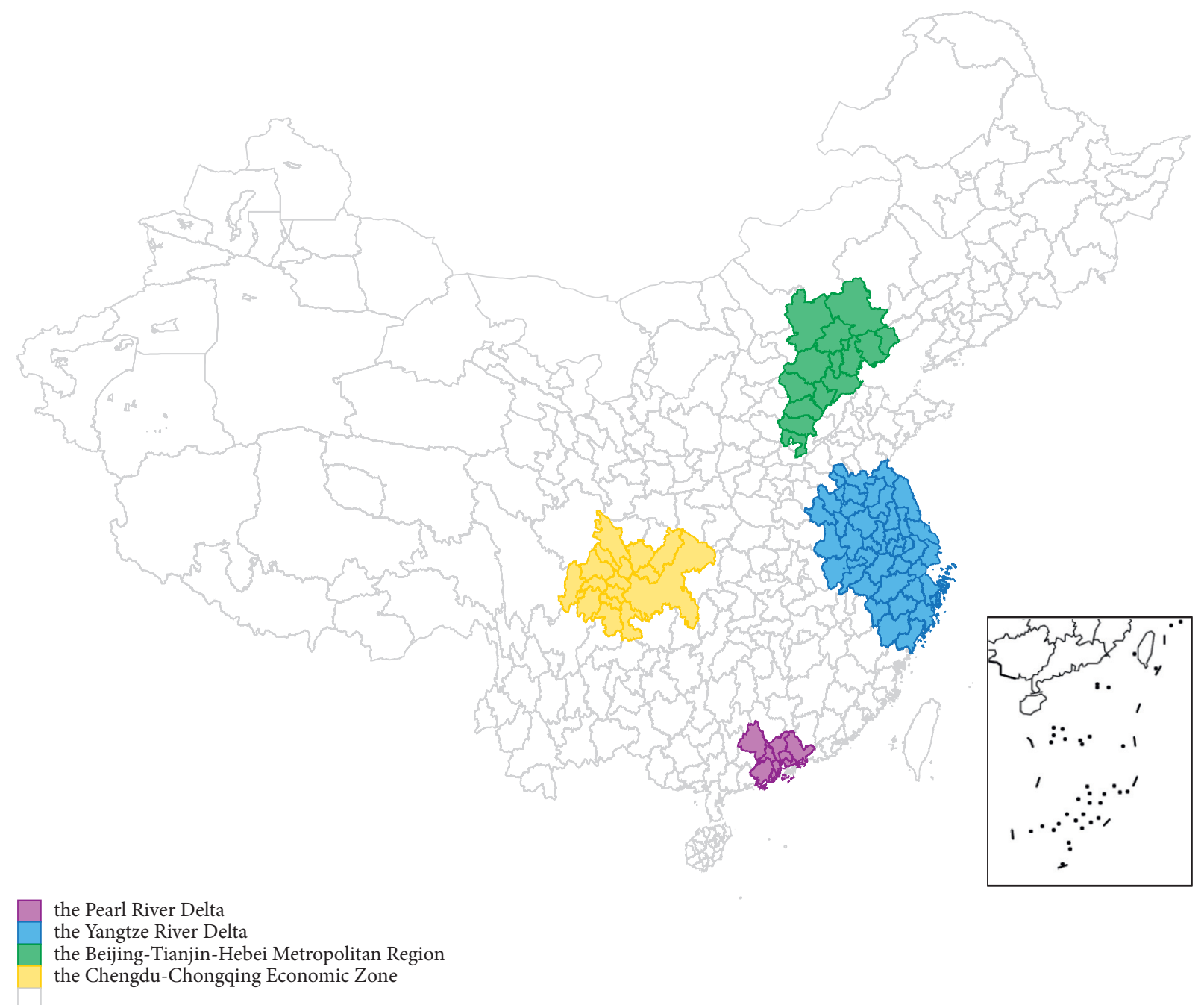

FIgURE 3: Four urban agglomerations in China.

We rank and equally divide the full sample cities into three groups to explore HSR's heterogeneous impact on green innovation performance in cities with different levels of green awareness. The grouped regression results are shown in Panel B of Table 6. The coefficients of HSR in all 12 columns are positive and significant at the level of at least $5 \%$. However, cities with high green sharing levels enjoy the most significant benefit from HSR, confirming that the regional level of green awareness plays an important role in promoting HSR's effect on green innovation. This result may contribute to the formulation of governments' green-innovation-related policy.

\section{Robustness Checks}

5.1. Parallel Trend Assumption Test. An important prerequisite for the DID model is to meet the parallel trend assumption. It requires that before the exogenous shock, there is no significant difference in the value trend of dependent variables between the experimental and the control group. We construct a model to test whether green innovation of the treatment group and that of the control group presented the same trend before the HSR connection. The model is set as follows:

$$
\mathrm{GI}_{i t}=\alpha_{0}+\sum_{j=-6}^{6} \delta_{j} \mathrm{HSR}_{i, t-j}+\gamma * X_{i, t-1}+u_{i}+v_{t}+\varepsilon_{i t},
$$

where $\operatorname{HSR}_{i, t-j}$ is a dummy variable; if city $i$ in year $t-j$ was connected to HSR, it takes the value of 1 and 0 , otherwise. We measure the HSR effect from six years before HSR connection to six years after. Therefore, $\delta_{-6}$ to $\delta_{-1}$ measure separately the average HSR's effect on green innovation in six years to one year before the HSR connection in city $i ; \delta_{o}$ measures the current treatment effect of HSR connection; $\delta_{1}$ to $\delta_{6}$ measure the average effect in one year to six years after connection. Taking the one year before HSR connection in each city as the benchmark group, if the confidence intervals of $\delta_{-6}$ to $\delta_{-2}$ contain zero, there is no significant difference in regional green innovation between the experimental group and the control group. Otherwise, the difference is significant and the parallel trend assumption is tenable.

Figure 4 shows the results of equation (8). For all four kinds of patents, the confidence intervals of the estimated 
TABLE 6: Heterogeneity analysis on urban development index and green sharing index.

\begin{tabular}{|c|c|c|c|c|c|c|}
\hline & \multicolumn{3}{|c|}{ Panel A: urban development index } & \multicolumn{3}{|c|}{ Panel B: green sharing index } \\
\hline & Low & $\begin{array}{c}\text { Medium } \\
\text { GUMA }\end{array}$ & High & Low & $\begin{array}{l}\text { Medium } \\
\text { GUMA }\end{array}$ & High \\
\hline & $(1)$ & $(2)$ & (3) & $(1)$ & $(2)$ & (3) \\
\hline L.HSR & $\begin{array}{c}0.0191 \\
(0.0152)\end{array}$ & $\begin{array}{l}0.0470^{* *} \\
(0.0232)\end{array}$ & $\begin{array}{l}0.271^{* * *} \\
(0.0707)\end{array}$ & $\begin{array}{l}0.0702^{* *} \\
(0.0325)\end{array}$ & $\begin{array}{l}0.119^{* * *} \\
(0.0371)\end{array}$ & $\begin{array}{l}0.264^{* * *} \\
(0.0652)\end{array}$ \\
\hline$R^{2}$ & 0.576 & 0.478 & 0.624 & 0.386 & 0.459 & 0.542 \\
\hline Test of group: coefficient difference & \multicolumn{3}{|c|}{ Medium vs. high } & Low vs. medium & Medium vs. high & Low vs. high \\
\hline \multirow[t]{2}{*}{ Observed difference } & \multicolumn{3}{|c|}{$-0.217^{* * *}$} & -0.049 & $\begin{array}{l}-0.145^{* *} \\
\text { GIA }\end{array}$ & $-0.194^{* * *}$ \\
\hline & $(4)$ & $(5)$ & (6) & $(4)$ & (5) & (6) \\
\hline L.HSR & $\begin{array}{l}0.00799 \\
(0.0132)\end{array}$ & $\begin{array}{l}0.0641^{* *} \\
(0.0249)\end{array}$ & $\begin{array}{l}0.318^{* * *} \\
(0.0895)\end{array}$ & $\begin{array}{l}0.135^{* * *} \\
(0.0478)\end{array}$ & $\begin{array}{l}0.125^{* * *} \\
(0.0433)\end{array}$ & $\begin{array}{l}0.289^{* * *} \\
(0.0853)\end{array}$ \\
\hline$R^{2}$ & 0.510 & 0.392 & 0.559 & 0.312 & 0.388 & 0.463 \\
\hline Test of group: coefficient difference & \multicolumn{3}{|c|}{ Medium vs. high } & Low vs. medium & Medium vs. high & Low vs. high \\
\hline \multirow[t]{2}{*}{ Observed difference } & \multicolumn{3}{|c|}{$-0.258^{* *}$} & 0.010 & $\begin{array}{l}-0.165^{* *} \\
G U M G\end{array}$ & $-0.154^{*}$ \\
\hline & (7) & $(8)$ & (9) & (7) & (8) & (9) \\
\hline L.HSR & $\begin{array}{c}0.0164 \\
(0.0125)\end{array}$ & $\begin{array}{l}0.0439^{* *} \\
(0.0183)\end{array}$ & $\begin{array}{l}0.254^{* * *} \\
(0.0626)\end{array}$ & $\begin{array}{l}0.0621^{* *} \\
(0.0306)\end{array}$ & $\begin{array}{l}0.105^{* * *} \\
(0.0332)\end{array}$ & $\begin{array}{l}0.254^{* * *} \\
(0.0590)\end{array}$ \\
\hline$R^{2}$ & 0.553 & 0.499 & 0.611 & 0.387 & 0.444 & 0.539 \\
\hline Test of group: coefficient difference & \multicolumn{3}{|c|}{ Medium vs. high } & Low vs. medium & Medium vs. high & Low vs. high \\
\hline \multirow[t]{2}{*}{ Observed difference } & & $\begin{array}{c}-0.211^{* * *} \\
G I G\end{array}$ & & -0.043 & $\begin{array}{l}-0.149^{* *} \\
\text { GIG }\end{array}$ & $-0.192^{* *}$ \\
\hline & $(10)$ & (11) & $(12)$ & $(10)$ & $(11)$ & (12) \\
\hline L.HSR & $\begin{array}{c}0.00238 \\
(0.00208)\end{array}$ & $\begin{array}{l}0.0147^{* * *} \\
(0.00487)\end{array}$ & $\begin{array}{c}0.0803^{* * *} \\
(0.0206)\end{array}$ & $\begin{array}{l}0.0231^{* *} \\
(0.00915)\end{array}$ & $\begin{array}{l}0.0298^{* * *} \\
(0.00941)\end{array}$ & $\begin{array}{c}0.0818^{* * *} \\
(0.0212)\end{array}$ \\
\hline$R^{2}$ & 0.532 & 0.391 & 0.543 & 0.312 & 0.381 & 0.465 \\
\hline Test of group: coefficient difference & \multicolumn{3}{|c|}{ Medium vs. high } & Low vs. medium & Medium vs. high & Low vs. high \\
\hline Observed difference & \multicolumn{3}{|c|}{$-0.077^{* * *}$} & -0.007 & $-0.052^{* *}$ & $-0.059^{* *}$ \\
\hline Controls & Yes & Yes & Yes & Yes & Yes & Yes \\
\hline Year & Yes & Yes & Yes & Yes & Yes & Yes \\
\hline City & Yes & Yes & Yes & Yes & Yes & Yes \\
\hline$N$ & 1072 & 1104 & 1105 & 1105 & 1104 & 1072 \\
\hline
\end{tabular}

Note: in Panel A, the estimation sample is divided into three groups based on cities' urban development index (i.e., cities with low, medium, and high urban development index). In Panel B, the estimation sample is split based on cities' green sharing index (i.e., cities with low, medium, and high green sharing index). The test of coefficient difference between groups is also carried out here using the bootstrap method. The bootstrap number in this paper is set to bs (1000). HSR and all control variables are lagged by one year. All regressions include city fixed effects and year fixed effects. Robust standard errors in parentheses are clustered at the city level. The symbols ${ }^{* * *},{ }^{* *}$, and ${ }^{*}$ indicate significance at the $1 \%, 5 \%$, and $10 \%$ levels, respectively.

coefficient $\delta_{j}$ in years before HSR connection contain zero, which means that the difference between the treatment group and the control group is not obvious before the opening of HSR, suggesting that the parallel trend assumption test has passed in this paper. The confidence intervals do not contain zero since the second year after the HSR connection. It means that the promoting effects of HSR on green innovation are positive and long-lasting, which is consistent with the estimation results in Section 3.1. Moreover, in the following six years after the HSR connection, the coefficient estimates of HSR increase monotonically, which means that the full impact of the HSR connection occurs with a lag of at least six years. One possible explanation is that after the reallocation of research resources caused by HSR connection, inventors in each city need sufficient time to learn and familiarize themselves with new resources and build up their innovative production capacities [83]. Overall, the parallel trend assumption is satisfied, and the multiperiod DID model is applicable.
5.2. Placebo Test. One of the challenges to assess the effect of the exogenous shock with the DID method is the omitted variable problem. It means that, in addition to the HSR connection, there will be other unobserved factors affecting regional green innovation in the external environment. To solve this problem, we implement a placebo test by artificially advancing each HSR city's HSR connection time two and three years ahead, following X. Zhang et al. [50]. If we still capture a significant impact of two false HSR connection dummy variables on regional green innovation, it means that the problem of serious omitted variables exists and the baseline regression results are biased. Otherwise, we can argue that our baseline results are robust.

The result of the placebo test is shown in Table 7 . We can see that after advancing the HSR connection time by either two or three years, the average effects of HSR on four kinds of green patents become statistically insignificant. Thus, we can conclude that the problem of other unanticipated factors affecting regional green innovation is marginal. Hence, the 


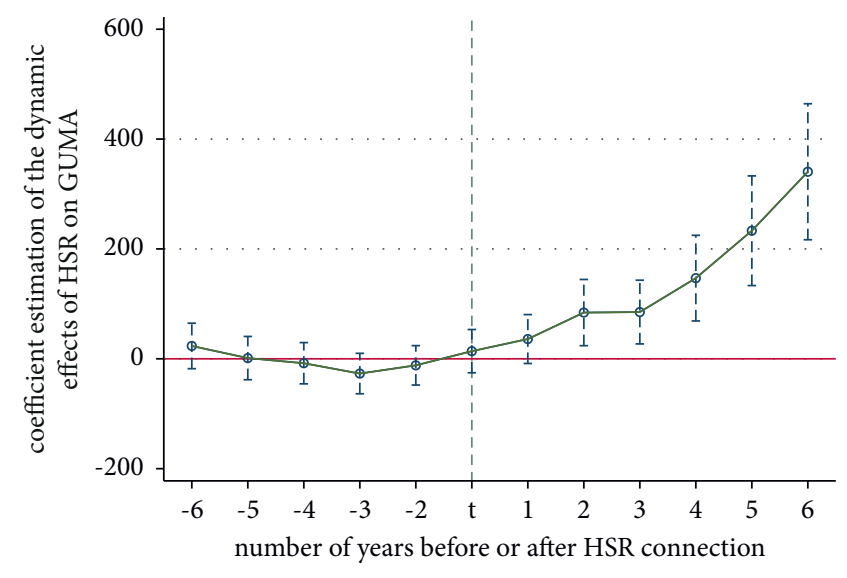

(a)

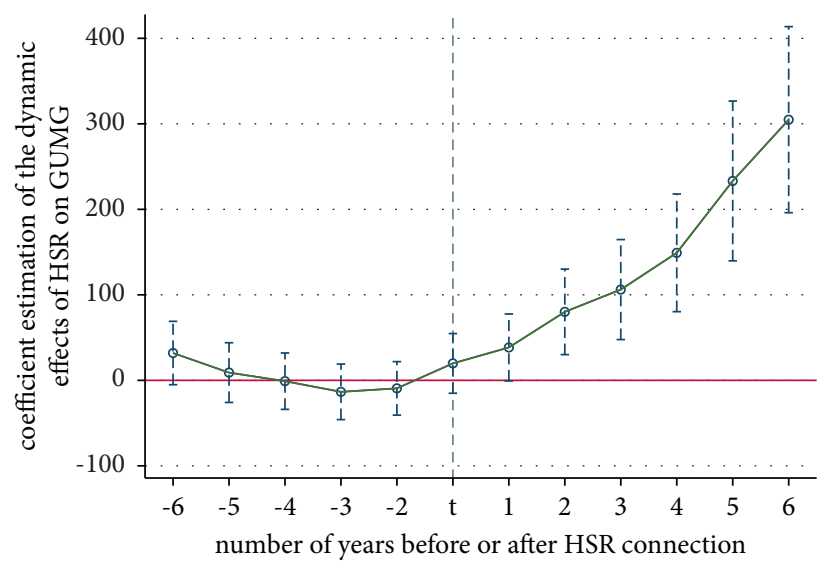

(c)

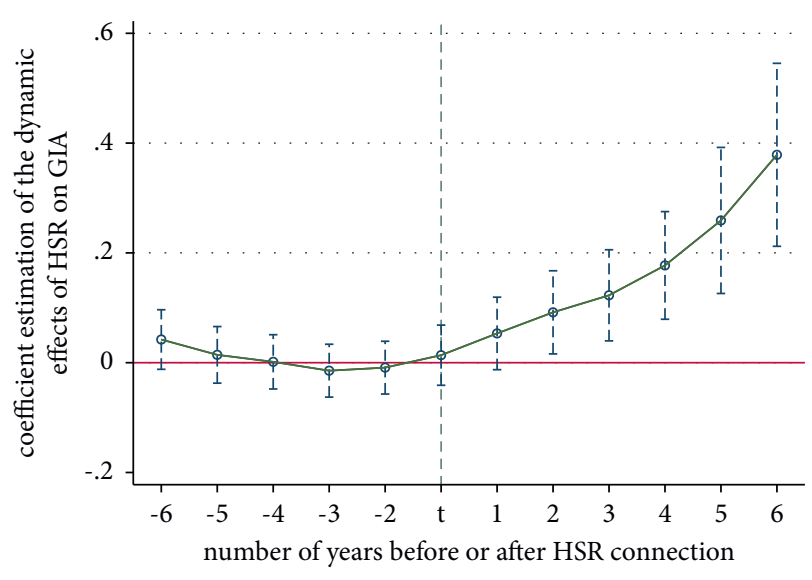

(b)

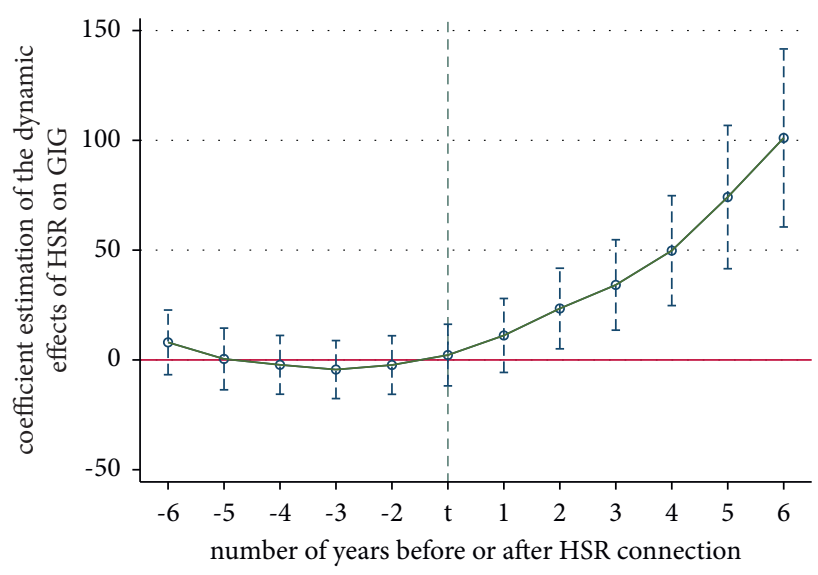

(d)

Figure 4: Dynamics of the effects on green innovation. Note: this graph plots the estimated coefficients on indicators of various years before and after HSR connection in four indicators of green innovation, respectively. Ninety-five percent confidence intervals, adjusted for clustering at the city level, are also plotted. According to the time of high-speed railway connection in each city, we generate thirteen dummy variables, which are 1-6 years before, current, 1-6 years after, respectively. The dummy variable of one year before was dropped as the benchmark group. All city-level controls are included and lagged by one year. Robust standard errors are clustered at the city level. (a) GUMA. (b) GIA. (c) GUMG. (d) GIG.

significant positive impact of HSR on regional green innovation is robust.

5.3. Instrumenting for HSR Connection. Reverse causality may exist. On the one hand, connection to the HSR network will promotes regional green innovation; on the other hand, cities with higher-level green innovation ability may be more developed and more likely to construct HSR. Instrumental variables (IVs) can be used to solve the problem of reverse causality.

For the IVs to be valid in our analysis, they should satisfy the relevance assumption of an instrument and affect today's regional green innovation only through their effects on the HSR network configuration. Following the spirit of Michaels [96] and Duranton and Turner $[97,98]$, who use historical or geographical information to construct IVs, we construct two IVs with historical data in this paper to reduce the endogenous estimation bias caused by reverse causality and further test the robustness of the empirical results. The two
IVs are (1) the interaction of the 1962 railway network in China and the number of cities connected to the HSR network in each city's province each year [99] and (2) the interaction of the RDLS and the year dummy variables $[49,100]$.

Firstly, we instrument the HSR connection with the 1962 railway network in China. The 1962 railways were constructed primarily to transport raw materials and manufacturing goods to provincial capitals for national defense purposes in China's interior regions. Given that the initial purpose of the HSR network was to serve passengers so that capacity in the original network can be freed up for freight service, most of the HSR lines designed in the original plan ran parallel to the then-existing railway lines [45]. Thus, there is a high relevance between the 1962 railway network and today's configuration of the HSR network. Given that the 1962 railway instrument is not time-varying, we augment it with the number of HSR cities in each province each year.

Secondly, we use the RDLS of each city as an IV of HSR connection. The RDLS is determined by geographical factors 
TABle 7: Placebo test.

\begin{tabular}{|c|c|c|c|c|c|c|c|c|}
\hline & $\begin{array}{c}(1) \\
\text { GUMA }\end{array}$ & $\begin{array}{c}(2) \\
\text { GIA }\end{array}$ & $\begin{array}{c}(3) \\
G U M G\end{array}$ & $\begin{array}{c}(4) \\
G I G\end{array}$ & $\begin{array}{c}(5) \\
\text { GUMA }\end{array}$ & $\begin{array}{l}(6) \\
\text { GIA }\end{array}$ & $\begin{array}{c}(7) \\
G U M G\end{array}$ & $\begin{array}{c}(8) \\
G I G\end{array}$ \\
\hline F2.HSR & $\begin{array}{c}0.0213 \\
(0.0158) \\
\end{array}$ & $\begin{array}{c}0.0103 \\
(0.0215) \\
\end{array}$ & $\begin{array}{c}0.0170 \\
(0.0146) \\
\end{array}$ & $\begin{array}{c}0.00453 \\
(0.00540) \\
\end{array}$ & & & & \\
\hline F3.HSR & & & & & $\begin{array}{c}-0.0157 \\
(0.0158)\end{array}$ & $\begin{array}{l}-0.0284 \\
(0.0211) \\
\end{array}$ & $\begin{array}{r}-0.0166 \\
(0.0153) \\
\end{array}$ & $\begin{array}{l}-0.00625 \\
(0.00537) \\
\end{array}$ \\
\hline L.lngdp & $\begin{array}{c}0.0615 \\
(0.0527) \\
\end{array}$ & $\begin{array}{c}0.0676 \\
(0.0622) \\
\end{array}$ & $\begin{array}{c}0.0528 \\
(0.0497) \\
\end{array}$ & $\begin{array}{l}0.00897 \\
(0.0144) \\
\end{array}$ & $\begin{array}{c}0.110 \\
(0.188)\end{array}$ & $\begin{array}{c}0.107 \\
(0.169) \\
\end{array}$ & $\begin{array}{l}0.0715 \\
(0.193) \\
\end{array}$ & $\begin{array}{c}-0.0107 \\
(0.164) \\
\end{array}$ \\
\hline L. $\ln p o p$ & $\begin{array}{l}0.167^{* * *} \\
(0.0468)\end{array}$ & $\begin{array}{l}0.196^{* * *} \\
(0.0597)\end{array}$ & $\begin{array}{l}0.155^{* * *} \\
(0.0468)\end{array}$ & $\begin{array}{c}0.0467^{* * *} \\
(0.0159)\end{array}$ & $\begin{array}{c}0.208^{* * *} \\
(0.0711)\end{array}$ & $\begin{array}{l}0.168^{* * *} \\
(0.0639)\end{array}$ & $\begin{array}{l}0.224^{* * *} \\
(0.0808)\end{array}$ & $\begin{array}{c}0.188^{* *} \\
(0.0791)\end{array}$ \\
\hline L.thirdpc & $\begin{array}{c}0.471^{* * *} \\
(0.144) \\
\end{array}$ & $\begin{array}{c}0.542^{* * *} \\
(0.201) \\
\end{array}$ & $\begin{array}{c}0.477^{* * *} \\
(0.137) \\
\end{array}$ & $\begin{array}{l}0.143^{* * *} \\
(0.0477) \\
\end{array}$ & $\begin{array}{l}0.175^{* * *} \\
(0.0465)\end{array}$ & $\begin{array}{l}0.162^{* * *} \\
(0.0483)\end{array}$ & $\begin{array}{l}0.195^{* * *} \\
(0.0500)\end{array}$ & $\begin{array}{l}0.161^{* * *} \\
(0.0478)\end{array}$ \\
\hline L.Infore & $\begin{array}{c}-0.0280^{* * *} \\
(0.00756)\end{array}$ & $\begin{array}{c}-0.0290^{* * *} \\
(0.00958)\end{array}$ & $\begin{array}{c}-0.0266^{* * *} \\
(0.00715)\end{array}$ & $\begin{array}{c}-0.00772^{* * *} \\
(0.00227)\end{array}$ & $\begin{array}{c}0.0353 \\
(0.0480)\end{array}$ & $\begin{array}{c}0.0436 \\
(0.0575)\end{array}$ & $\begin{array}{c}0.0236 \\
(0.0450)\end{array}$ & $\begin{array}{l}0.00109 \\
(0.0134)\end{array}$ \\
\hline L.roadpc & $\begin{array}{l}-0.00274 \\
(0.00292)\end{array}$ & $\begin{array}{l}-0.00188 \\
(0.00347)\end{array}$ & $\begin{array}{l}-0.00309 \\
(0.00272)\end{array}$ & $\begin{array}{l}-0.000360 \\
(0.000875)\end{array}$ & $\begin{array}{l}0.147^{* * *} \\
(0.0504)\end{array}$ & $\begin{array}{l}0.157^{* * *} \\
(0.0599)\end{array}$ & $\begin{array}{l}0.144^{* * *} \\
(0.0520)\end{array}$ & $\begin{array}{c}0.0423^{* *} \\
(0.0179)\end{array}$ \\
\hline L.buspc & $\begin{array}{c}0.00852^{* *} \\
(0.00391)\end{array}$ & $\begin{array}{c}0.0117^{* *} \\
(0.00498) \\
\end{array}$ & $\begin{array}{c}0.00783^{* *} \\
(0.00373) \\
\end{array}$ & $\begin{array}{c}0.00291^{* *} \\
(0.00122)\end{array}$ & $\begin{array}{c}0.524^{* * *} \\
(0.140)\end{array}$ & $\begin{array}{c}0.646^{* * *} \\
(0.193)\end{array}$ & $\begin{array}{c}0.531^{* * *} \\
(0.137)\end{array}$ & $\begin{array}{l}0.155^{* * *} \\
(0.0460)\end{array}$ \\
\hline L.lngre & $\begin{array}{r}-0.0129 \\
(0.0186) \\
\end{array}$ & $\begin{array}{l}-0.0316 \\
(0.0248) \\
\end{array}$ & $\begin{array}{c}-0.00856 \\
(0.0184) \\
\end{array}$ & $\begin{array}{l}-0.00640 \\
(0.00666) \\
\end{array}$ & $\begin{array}{c}-0.0258^{* * *} \\
(0.00686) \\
\end{array}$ & $\begin{array}{c}-0.0271^{* * *} \\
(0.00877) \\
\end{array}$ & $\begin{array}{c}-0.0256^{* * *} \\
(0.00667) \\
\end{array}$ & $\begin{array}{c}-0.00732^{* * *} \\
(0.00211)\end{array}$ \\
\hline L.lneduc & $\begin{array}{l}-0.0847 \\
(0.0598) \\
\end{array}$ & $\begin{array}{l}-0.0520 \\
(0.0675) \\
\end{array}$ & $\begin{array}{l}-0.0877 \\
(0.0581)\end{array}$ & $\begin{array}{c}-0.00706 \\
(0.0150) \\
\end{array}$ & $\begin{array}{l}-0.00391 \\
(0.00288) \\
\end{array}$ & $\begin{array}{l}-0.00276 \\
(0.00343) \\
\end{array}$ & $\begin{array}{c}-0.00377 \\
(0.00279) \\
\end{array}$ & $\begin{array}{c}-0.000620 \\
(0.000896) \\
\end{array}$ \\
\hline L.policy1 & $\begin{array}{c}0.0446 \\
(0.0486) \\
\end{array}$ & $\begin{array}{c}0.0272 \\
(0.0610) \\
\end{array}$ & $\begin{array}{c}0.0473 \\
(0.0469) \\
\end{array}$ & $\begin{array}{l}0.00626 \\
(0.0142) \\
\end{array}$ & $\begin{array}{l}0.00766^{* *} \\
(0.00374) \\
\end{array}$ & $\begin{array}{l}0.00901^{* *} \\
(0.00457) \\
\end{array}$ & $\begin{array}{c}0.00729^{* *} \\
(0.00370) \\
\end{array}$ & $\begin{array}{c}0.00244^{* *} \\
(0.00117) \\
\end{array}$ \\
\hline L.policy2 & $\begin{array}{c}0.311^{* * *} \\
(0.119)\end{array}$ & $\begin{array}{l}0.271^{*} \\
(0.142) \\
\end{array}$ & $\begin{array}{c}0.300^{* *} \\
(0.116)\end{array}$ & $\begin{array}{c}0.0619^{*} \\
(0.0334)\end{array}$ & $\begin{array}{c}-0.00619 \\
(0.0165) \\
\end{array}$ & $\begin{array}{c}-0.0181 \\
(0.0218) \\
\end{array}$ & $\begin{array}{c}-0.00374 \\
(0.0169) \\
\end{array}$ & $\begin{array}{l}-0.00419 \\
(0.00620) \\
\end{array}$ \\
\hline L.policy3 & $\begin{array}{l}0.0443^{* * *} \\
(0.00992)\end{array}$ & $\begin{array}{c}0.0789^{* * *} \\
(0.0150)\end{array}$ & $\begin{array}{l}0.0247^{* * *} \\
(0.00821)\end{array}$ & $\begin{array}{l}0.0151^{* * *} \\
(0.00260)\end{array}$ & $\begin{array}{l}-0.0882 \\
(0.0586)\end{array}$ & $\begin{array}{l}-0.0633 \\
(0.0648)\end{array}$ & $\begin{array}{l}-0.0865 \\
(0.0572)\end{array}$ & $\begin{array}{c}-0.00993 \\
(0.0148)\end{array}$ \\
\hline cons & $\begin{array}{l}-0.773 \\
(1.029) \\
\end{array}$ & $\begin{array}{l}-1.289 \\
(1.325) \\
\end{array}$ & $\begin{array}{l}-0.598 \\
(0.986) \\
\end{array}$ & $\begin{array}{l}-0.272 \\
(0.307) \\
\end{array}$ & $\begin{array}{l}-0.326 \\
(1.019) \\
\end{array}$ & $\begin{array}{l}-0.738 \\
(1.282) \\
\end{array}$ & $\begin{array}{l}-0.189 \\
(0.997) \\
\end{array}$ & $\begin{array}{l}-0.124 \\
(0.305) \\
\end{array}$ \\
\hline Year & Yes & Yes & Yes & Yes & Yes & Yes & Yes & Yes \\
\hline City & Yes & Yes & Yes & Yes & Yes & Yes & Yes & Yes \\
\hline $\mathrm{N}$ & 3362 & 3362 & 3362 & 3362 & 3082 & 3082 & 3082 & 3082 \\
\hline$R^{2}$ & 0.262 & 0.203 & 0.253 & 0.204 & 0.247 & 0.186 & 0.247 & 0.190 \\
\hline
\end{tabular}

Note: this table reports the results of the parallel trend hypothesis test, which are regressions of regional green innovation on two dummy variables by artificially advancing each HSR city's HSR connection time two and three years ahead. All control variables are included and lagged by one year. All regressions include city fixed effects and year fixed effects. Robust standard errors in parentheses are clustered at the city level. The symbols ${ }^{* * *},{ }^{* *}$, and ${ }^{*}$ indicate significance at the $1 \%, 5 \%$, and $10 \%$ levels, respectively.

and thus has no direct impact on regional green innovation performance but will affect the difficulty and cost of HSR construction. As we can see in Figure 1, China's HSR network is unevenly distributed. It spreads over the plains and low-altitude areas in the east, while in the high-altitude mountainous areas and plateaus of the west, many cities have not had access to the HSR network yet [11]. Thus, the second IV in this paper is constructed as the RDLS multiplying the year dummy variable.

The estimation results of two IVs are reported in Panel A and Panel B of Table 8, respectively. (Before reporting the test results of the IV method, this paper conducts the Hausman test on the core explanatory variables and IVs, and the results show that the explanatory variables were endogenous.) The results of the first-stage regression are shown in Column (1) in each panel. Column (1) of Panel A shows a significant positive correlation between the 1962 railway connection and the HSR connection. The first-stage F value is 157.7, and the Kleibergen-Paap rk Wald F statistic is 304.951, both conforming to the empirical rule and rejecting the null hypothesis of the weak IV. Columns (2-4) of Panel A show the estimation results with the first IV. The coefficients of HSR are still significantly positive, confirming our baseline results remain reliable with the HSR connection indicator instrumented with a hybrid of the 1962 railway connection and the number of HSR cities in each province each year.

Column (1) of Panel B of Table 8 shows a significant negative correlation between each year's RDLS and the HSR connection. The first-stage F value is 41.444 , and the Kleibergen-Paap rk Wald F statistic is 49.765 , both of which exclude the problem of weak IVs. Columns (2-4) of Panel B show the estimation results of using the RDLS as an IV. The results show that the coefficients of HSR remain significantly positive, proving that our baseline results are still robust with HSR instrumented with each city's RDLS times the year 
TABLE 8: IV estimation.

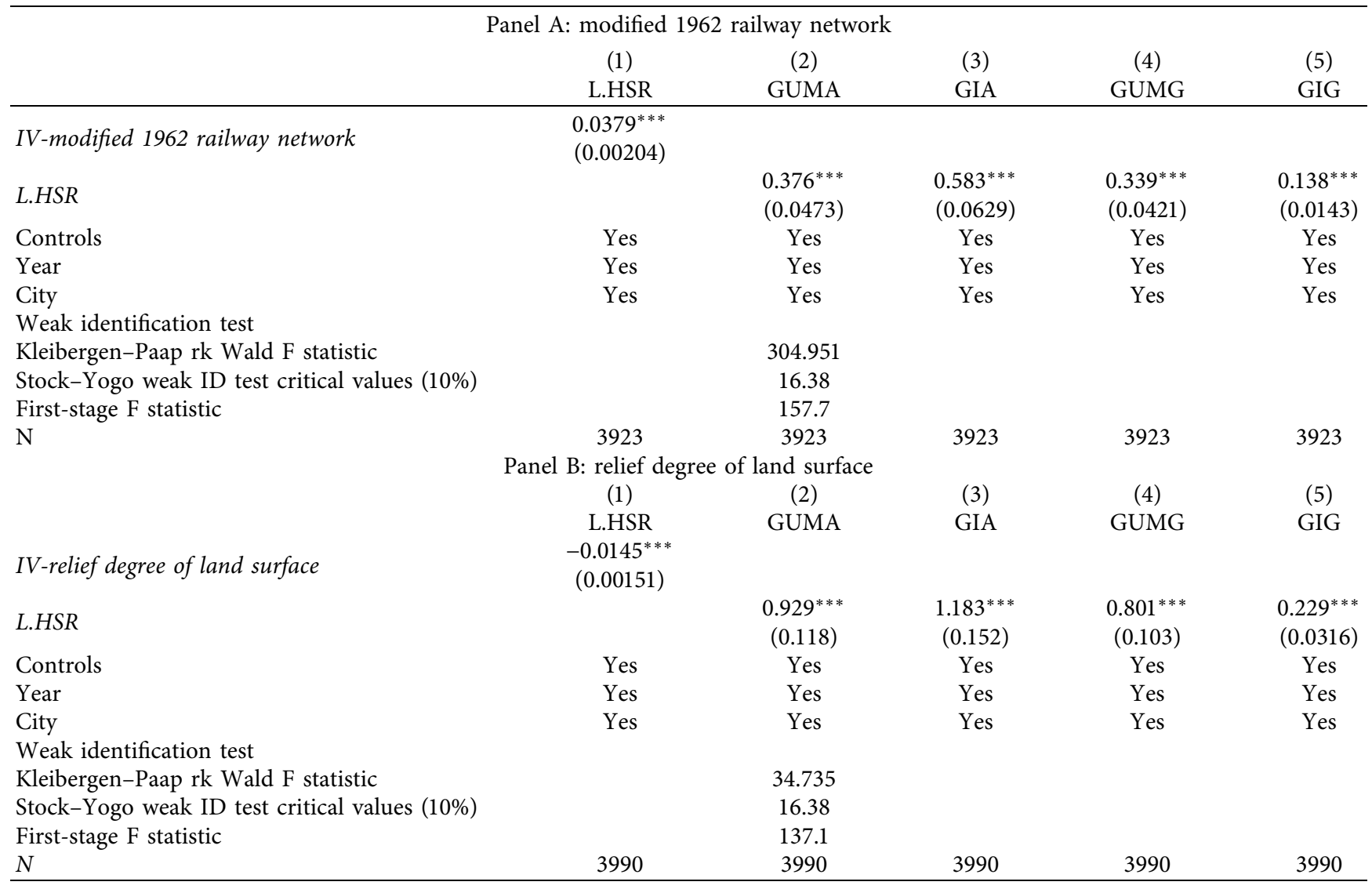

Note: the estimation sample includes 285 prefecture level and above cities in China. The sample period is from 2005 to 2018. Dependent variables are indicated by column titles in italics. All control variables are included and lagged by one year. All regressions include city fixed effects and year fixed effects. Robust standard errors in parentheses are clustered at the city level. The symbols ${ }^{* * *},{ }^{* *}$, and ${ }^{*}$ indicate significance at the $1 \%, 5 \%$, and $10 \%$ levels, respectively. We use the Kleibergen-Paap rk Wald F statistic to test for weak identification of the endogenous variables [101]. The critical value compiled by Stock and Yogo [102] is 16.38. Our results are also robust to the "rule of thumb" of Staiger and Stock [103], which requires the first-stage F statistic to be larger than 10.

dummy variable. The above analyses show that solving the endogeneity problem does not change our baseline regression results, indicating that the conclusions of this paper are reliable.

5.4. Alternative Explanatory Variables. Some prefecturelevel cities may have several HSR stations. For instance, Beijing has three HSR stations, namely, Beijing South, Beijing West, and Yizhuang. Each station may also have multiple HSR lines running through. For example, Beijing South has the Beijing-Tianjin Intercity Railway Line as well as the Beijing-Guangzhou HSR Line. To test the robustness of our baseline results, we substitute the number of HSR stations (Stations) and the number of HSR lines (Lines) in each city each year for the dummy variable HSR as the core explanatory variable, respectively.

Each HSR station is counted into Stations since the year the station passed through the first HSR line, instead of the year the station was built, because HSR stations are usually built several years before the first HSR line is opened. Considering some HSR stations were subordinated to different prefecture-level cities in different years, such as
Qufudong HSR Station which belonged to Jining in 2011 and then belonged to Qufu in 2019, we adjust them according to time. We then sum up the number of HSR lines of each HSR station in each city each year to get the number of Lines. It should be noted that some HSR lines were opened at the end of the year and we treat those HSR lines opened at the second half of the year with a one-year lag.

The regression results of the number of HSR stations and HSR lines as the core explanatory variables are shown in Table 9. The results show that both the number of HSR stations and HSR lines have significantly positive effects on the number of green patents at the $1 \%$ level. An additional HSR station can averagely increase regional GUMA, GIA, GUMG, and GIG by 87, 118, 76, and 25 per year, respectively, and an additional HSR line has a similar outcome. These results further support the validity of our baseline results.

5.5. Influence of the Natural Environment. When in the attempt to exploring the rationale behind regional green innovation performance, extant studies primarily consider the effect of economic and regulatory factors on green innovation when constructing the series of control variables, as 
TABLE 9: Alternative measure.

\begin{tabular}{|c|c|c|c|c|c|c|c|c|}
\hline & $\begin{array}{c}(1) \\
\text { GUMA }\end{array}$ & $\begin{array}{l}(2) \\
\text { GIA }\end{array}$ & $\begin{array}{c}(3) \\
G U M G\end{array}$ & $\begin{array}{l}(4) \\
G I G\end{array}$ & $\begin{array}{c}(5) \\
\text { GUMA }\end{array}$ & $\begin{array}{l}(6) \\
\text { GIA }\end{array}$ & $\begin{array}{c}(7) \\
G U M G\end{array}$ & $\begin{array}{c}(8) \\
G I G\end{array}$ \\
\hline L.Stations & $\begin{array}{l}0.0872^{* * *} \\
(0.00924)\end{array}$ & $\begin{array}{l}0.118^{* * *} \\
(0.0123)\end{array}$ & $\begin{array}{l}0.0764^{* * *} \\
(0.00838)\end{array}$ & $\begin{array}{l}0.0252^{* * *} \\
(0.00275)\end{array}$ & & & & \\
\hline L.Lines & & & & & $\begin{array}{c}0.0870^{* * *} \\
(0.00966)\end{array}$ & $\begin{array}{l}0.119^{* * *} \\
(0.0128)\end{array}$ & $\begin{array}{c}0.0763^{* * *} \\
(0.00866)\end{array}$ & $\begin{array}{l}0.0250^{* * *} \\
(0.00296)\end{array}$ \\
\hline Controls & Yes & Yes & Yes & Yes & Yes & Yes & Yes & Yes \\
\hline Year & Yes & Yes & Yes & Yes & Yes & Yes & Yes & Yes \\
\hline City & Yes & Yes & Yes & Yes & Yes & Yes & Yes & Yes \\
\hline$N$ & 3923 & 3923 & 3923 & 3923 & 3923 & 3923 & 3923 & 3923 \\
\hline$R^{2}$ & 0.472 & 0.444 & 0.455 & 0.408 & 0.496 & 0.481 & 0.478 & 0.432 \\
\hline
\end{tabular}

Note: the estimation sample includes 285 prefecture level and above cities in China. The sample period is from 2005 to 2018. Dependent variables are indicated by column titles in italics. Stations and Lines and all control variables are included and lagged by one year. All regressions include city fixed effects and year fixed effects. Robust standard errors in parentheses are clustered at the city level. The symbols ${ }^{* * *},{ }^{* *}$, and ${ }^{*}$ indicate significance at the $1 \%, 5 \%$, and $10 \%$ levels, respectively.

TABLE 10: Influence of the natural environment: temperature.

\begin{tabular}{|c|c|c|c|c|}
\hline & $\begin{array}{c}(1) \\
G U M A\end{array}$ & $\begin{array}{c}(2) \\
\text { GIA } \\
\end{array}$ & $\begin{array}{c}(3) \\
G U M G \\
\end{array}$ & $\begin{array}{c}(4) \\
G I G \\
\end{array}$ \\
\hline L.HSR & $\begin{array}{l}0.236^{* * *} \\
(0.0419)\end{array}$ & $\begin{array}{l}0.293^{* * *} \\
(0.0544)\end{array}$ & $\begin{array}{l}0.222^{* * *} \\
(0.0384)\end{array}$ & $\begin{array}{c}0.0718^{* * *} \\
(0.0132) \\
\end{array}$ \\
\hline L.temp & $\begin{array}{r}-0.00129^{* *} \\
(0.000535) \\
\end{array}$ & $\begin{array}{r}-0.00181^{* *} \\
(0.000698) \\
\end{array}$ & $\begin{array}{c}-0.000892^{* *} \\
(0.000416) \\
\end{array}$ & $\begin{array}{c}-0.000422^{* * *} \\
(0.000136)\end{array}$ \\
\hline L.lngdp & $\begin{array}{l}0.255^{* * *} \\
(0.0921) \\
\end{array}$ & $\begin{array}{c}0.251^{* *} \\
(0.104) \\
\end{array}$ & $\begin{array}{l}0.213^{* * *} \\
(0.0804) \\
\end{array}$ & $\begin{array}{c}0.0436^{*} \\
(0.0233) \\
\end{array}$ \\
\hline L.lnpop & $\begin{array}{c}0.530^{* *} \\
(0.204) \\
\end{array}$ & $\begin{array}{l}0.710^{* *} \\
(0.280)\end{array}$ & $\begin{array}{c}0.503^{* *} \\
(0.194)\end{array}$ & $\begin{array}{l}0.148^{* *} \\
(0.0627)\end{array}$ \\
\hline L.thirdpc & $\begin{array}{l}0.625^{* *} \\
(0.269) \\
\end{array}$ & $\begin{array}{l}0.735^{* *} \\
(0.364) \\
\end{array}$ & $\begin{array}{c}0.622^{* *} \\
(0.241) \\
\end{array}$ & $\begin{array}{c}0.188^{* *} \\
(0.0848) \\
\end{array}$ \\
\hline L.Inforeignca & $\begin{array}{l}-0.0183 \\
(0.0118) \\
\end{array}$ & $\begin{array}{c}-0.00947 \\
(0.0147) \\
\end{array}$ & $\begin{array}{l}-0.0167 \\
(0.0105) \\
\end{array}$ & $\begin{array}{l}-0.00483 \\
(0.00342) \\
\end{array}$ \\
\hline L.roadpc & $\begin{array}{l}-0.00746 \\
(0.00460) \\
\end{array}$ & $\begin{array}{l}-0.00414 \\
(0.00610) \\
\end{array}$ & $\begin{array}{r}-0.00719^{*} \\
(0.00416) \\
\end{array}$ & $\begin{array}{l}-0.00110 \\
(0.00143) \\
\end{array}$ \\
\hline L.buspc & $\begin{array}{c}0.0117 \\
(0.00751) \\
\end{array}$ & $\begin{array}{c}0.0205^{* *} \\
(0.0103) \\
\end{array}$ & $\begin{array}{c}0.0112^{*} \\
(0.00675)\end{array}$ & $\begin{array}{l}0.00490^{* *} \\
(0.00228)\end{array}$ \\
\hline L.lngreenland & $\begin{array}{l}-0.0370 \\
(0.0321) \\
\end{array}$ & $\begin{array}{l}-0.0613 \\
(0.0430) \\
\end{array}$ & $\begin{array}{l}-0.0281 \\
(0.0305) \\
\end{array}$ & $\begin{array}{l}-0.0119 \\
(0.0111)\end{array}$ \\
\hline L.lneduc & $\begin{array}{c}-0.219^{* *} \\
(0.0963) \\
\end{array}$ & $\begin{array}{l}-0.155 \\
(0.115) \\
\end{array}$ & $\begin{array}{c}-0.221^{* *} \\
(0.0900)\end{array}$ & $\begin{array}{l}-0.0316 \\
(0.0254)\end{array}$ \\
\hline L.policy 1 & $\begin{array}{c}0.0282 \\
(0.0720) \\
\end{array}$ & $\begin{array}{l}-0.0152 \\
(0.0980) \\
\end{array}$ & $\begin{array}{c}0.0432 \\
(0.0672) \\
\end{array}$ & $\begin{array}{l}0.00234 \\
(0.0228)\end{array}$ \\
\hline L.policy2 & $\begin{array}{c}0.334^{*} \\
(0.170) \\
\end{array}$ & $\begin{array}{c}0.213 \\
(0.221) \\
\end{array}$ & $\begin{array}{c}0.342^{* *} \\
(0.159) \\
\end{array}$ & $\begin{array}{c}0.0603 \\
(0.0516) \\
\end{array}$ \\
\hline L.policy3 & $\begin{array}{c}0.0857^{* *} \\
(0.0393) \\
\end{array}$ & $\begin{array}{l}0.0971^{*} \\
(0.0534)\end{array}$ & $\begin{array}{l}0.106^{* * *} \\
(0.0372)\end{array}$ & $\begin{array}{l}0.00848 \\
(0.0115) \\
\end{array}$ \\
\hline cons & $\begin{array}{c}-4.157^{* *} \\
(1.763)\end{array}$ & $\begin{array}{c}-5.874^{* *} \\
(2.455)\end{array}$ & $\begin{array}{c}-3.478^{* *} \\
(1.611)\end{array}$ & $\begin{array}{c}-1.104^{* *} \\
(0.539)\end{array}$ \\
\hline Year & Yes & Yes & Yes & Yes \\
\hline City & Yes & Yes & Yes & Yes \\
\hline $\mathrm{N}$ & 2187 & 2187 & 2187 & 2187 \\
\hline$R^{2}$ & 0.411 & 0.356 & 0.407 & 0.340 \\
\hline
\end{tabular}

Note: this table shows the results of the baseline model augmented with the control variable of the annual mean temperature of each city (temp). The estimation sample includes 160 prefecture level and above cities in China. The sample period is from 2005 to 2018. Dependent variables are indicated by column titles in italics. HSR and temp and all other control variables are included and lagged by one year. All regressions include city fixed effects and year fixed effects. Robust standard errors in parentheses are clustered at the city level. The symbols ${ }^{* * *},{ }^{* *}$, and ${ }^{*}$ indicate significance at the $1 \%, 5 \%$, and $10 \%$ levels, respectively. 
discussed in Section 1. However, the possible influence of the natural environment is largely ignored.

It seems intuitive that the green innovation behavior is likely to associate with geographic or climatological factors which are not under the control of the city. For instance, cities with higher atmospheric temperatures may emphasize more on green innovation to achieve unified carbon or other emission targets [104]. However, local governments may expect the adverse impact of extreme temperature on economic output and then try to alleviate this impact by reducing the enforcement intensity of environmental regulations [105]. In addition, not agreeable temperature may make workers less focused and less productive [106], particularly in the high-temperature environment [107]. Daily temperatures also have a U-shape relationship with annual energy consumption, affecting the cost of enterprises and then the decision on the expenditure on R\&D [108].

Following the spirit of Wang et al. [104], we include the regional temperature as an indicator of the natural environment to examine its effect on regional green innovation activity and test the robustness of our baseline regression. We use the mean annual temperature of each city each year (in degrees Celsius) (temp) as the additional control variable. These data are obtained from the China Environment Statistical Yearbooks. Due to the unavailability of all cities' annual temperatures, the final sample includes $2240 \mathrm{ob}-$ servations across 160 cities from 2005 to 2018. The regression results are shown in Table 10. The coefficient of temp is statistically significant at the $1 \%$ level and negatively related to four kinds of patents, which means that temperature has an influence on regional green innovation output. The average treatment effect of HSR connection remains significantly positive at the $1 \%$ level, which demonstrates the robustness of our empirical results.

\section{Conclusions and Discussion}

This paper has used HSR in China as a quasi-natural experiment to examine whether the HSR connection can encourage regional green innovation. Using the application number and the grant number of green utility model patents and green invention patents on the prefectural level as the proxy indicators of regional green innovation, we construct an annual panel of city-level data from 2005 to 2018. Our empirical strategy is a time-varying DID framework with city and year fixed effects and various city-level characteristics as controls. Our empirical results indicate that HSR has a strong and persistent positive effect on regional green innovation. After examining two potential mechanisms, we find evidence that HSR can promote regional green innovation through facilitating labor and research capital mobility. We further explore the cross-sectional heterogeneity of our main results and find that the positive effect of HSR connection on green innovation is more pronounced in the eastern and western regions, in YRD and CY, in cities with a higher level of development and cities which attach more importance to the eco-friendly concept in local economic development. A variety of alternative tests proves the robustness of our estimation.
Our study suggests that cities should have adequate innovation resources to perform regional green innovation effectively. It is, therefore, of great value to find ways to reduce the hinderance of labor mobility and research capital mobility and improve the scope and efficiency of matching pool. Our findings support that HSR connection can act as an important role in reducing financing constraints, facilitating labor flow, and then promoting green innovation. We shed light on the overall consequences of the improvement of transport infrastructure on cities' eco-friendly economy development.

While we show that HSR in China appears to have a positive and long-term effect on innovation, we note that the research can be further improved in at least three important directions. First, although using green patent as a measure of green innovation output has been widely accepted and used as an indicator of new environmental-friendly technology creation, we fully acknowledge the limitations of using green patents as a proxy for regional green innovation. Not all new green innovations are patented. Some green innovations do not satisfy patentability criteria, and some may not be applied for patents for that company may wish to safeguard the confidentiality of core technology for competitive advantages. Second, when measuring the labor mobility, we use the city's labor market size as the indicator in the gravity model. However, the amount of R\&D labor will be a better indicator to measure human capital flow effect on green innovation. Unfortunately, these data at the city level are unavailable to us. Third, in the case of research capital measurement, our data do not allow us to measure the regional specific input of capital to R\&D from both the local government and the enterprises. Hence, we interpret the government expenditure on science and technology as a general measure of the regional research capital size. Future research could leverage fresh perspectives and new means of measurement to further explore the promotion effect of HSR on green innovation and the influence of resource mobility.

\section{Data Availability}

The datasets used or analysed during the current study are available from the corresponding author on reasonable request.

\section{Conflicts of Interest}

The authors declare that they have no conflicts of interest.

\section{Acknowledgments}

This research was funded by the Fundamental Research Funds for the Central Universities (grant no. 2021YJS072).

\section{References}

[1] K. Spiekermann and M. Wegener, "The shrinking continent: new time - space maps of Europe," Environment and Planning B: Planning and Design, vol. 21, no. 6, pp. 653-673, 1994. 
[2] D. Albalate and G. Bel, "High-speed rail: lessons for policy makers from experiences abroad," Public Administration Review, vol. 72, no. 3, pp. 336-349, 2012.

[3] M. Givoni, "Development and impact of the modern highspeed train: a review," Transport Reviews, vol. 26, no. 5, pp. 593-611, 2006.

[4] R. Vickerman, "High-speed rail and regional development: the case of intermediate stations," Journal of Transport Geography, vol. 42, pp. 157-165, 2015.

[5] J. Jiao, J. Wang, and F. Jin, "Impacts of high-speed rail lines on the city network in China," Journal of Transport Geography, vol. 60, pp. 257-266, 2017.

[6] S. Jia, C. Zhou, and C. Qin, "No difference in effect of highspeed rail on regional economic growth based on match effect perspective," Transportation Research Part A: Policy and Practice, vol. 106, pp. 144-157, 2017.

[7] F. Wang, X. Wei, J. Liu, L. He, and M. Gao, "Impact of highspeed rail on population mobility and urbanisation: a case study on Yangtze River Delta urban agglomeration, China," Transportation Research Part A: Policy and Practice, vol. 127, pp. 99-114, 2019.

[8] S. Shao, Z. Tian, and L. Yang, "High speed rail and urban service industry agglomeration: evidence from China's Yangtze River Delta region," Journal of Transport Geography, vol. 64, pp. 174-183, 2017.

[9] W. Zhang, X. Tian, and A. Yu, "Is high-speed rail a catalyst for the fourth industrial revolution in China? Story of enhanced technology spillovers from venture capital," Technological Forecasting and Social Change, vol. 161, 2020.

[10] Y. Li, Z. Chen, and P. Wang, "Impact of high-speed rail on urban economic efficiency in China," Transport Policy, vol. 97, pp. 220-231, 2020.

[11] Y. Huang and H. Zong, "Has high-speed railway promoted spatial equity at different levels? A case study of inland mountainous area of China," Cities, vol. 110, Article ID 103076, 2021.

[12] H. Fan, "Impacts of high-speed rail stations opening on the regional innovation level -analysis based on scoring tendency matching model," Modern Economy, vol. 11, pp. 383-398, 2020.

[13] L. Aldieri, M. Kotsemir, and C. P. Vinci, "Environmental innovations and productivity: empirical evidence from Russian regions," Resources Policy, vol. 74, 2021.

[14] D. B. Audretsch and P. E. Stephan, "Company-scientist locational links: the case of biotechnology," The American Economic Review, vol. 86, 1996.

[15] S. X. Zeng, C. M. Tam, Z. M. Deng, and V. W. Y. Tam, "ISO 14000 and the construction industry: survey in China," Journal of Management in Engineering, vol. 19, no. 3, pp. 107-115, 2003.

[16] C. Lin and Y. Ho, "Determinants of green practice adoption for logistics companies in China," Journal of Business Ethics, vol. 98, no. 1, pp. 67-83, 2011.

[17] T. H. Oum and X. Fu, "Impacts of airports on airline competition: focus on airport performance and airportairline vertical relations," Competitive Interaction between Airports, Airlines and High-Speed Rail, OECD Publishing, Paris, France, 2009.

[18] L. C. Leonidou, P. Christodoulides, L. P. Kyrgidou, and D. Palihawadana, "Internal drivers and performance consequences of small firm green business strategy: the moderating role of external forces," Journal of Business Ethics, vol. 140, no. 3, pp. 585-606, 2017.
[19] D. Cao, J. Li, G. Liu, and R. Mei, "Can decentralization drive green innovation? A game theoretical analysis of manufacturer encroachment selection with consumer green awareness," Processes, vol. 9, 2021.

[20] L. d. A. Rezende, A. C. Bansi, M. F. R. Alves, and S. V. R. Galina, "Take your time: examining when green innovation affects financial performance in multinationals," Journal of Cleaner Production, vol. 233, pp. 993-1003, 2019.

[21] P. Beneito, "Choosing among alternative technological strategies: an empirical analysis of formal sources of innovation," Research Policy, vol. 32, no. 4, pp. 693-713, 2003.

[22] J. M. Ureña, P. Menerault, and M. Garmendia, "The highspeed rail challenge for big intermediate cities: a national, regional and local perspective," Cities, vol. 26, pp. 266-279, 2009.

[23] C. A. Weber, J. R. Current, and W. C. Benton, "Vendor selection criteria and methods," European Journal of Operational Research, vol. 50, no. 1, pp. 2-18, 1991.

[24] J. Willigers and B. W. Van, "High-speed rail and office location choices. A stated choice experiment for The Netherlands," Journal of Transport Geography, vol. 19, no. 4, pp. 745-754, 2011.

[25] W. A. Ben, L. Hikkerova, and J. M. Sahut, "External knowledge sources, green innovation and performance," Technological Forecasting and Social Change, vol. 129, pp. 210-220, 2018.

[26] A. B. Bernard, A. Moxnes, and Y. U. Saito, "Production networks, geography, and firm performance," Journal of Political Economy, vol. 127, no. 2, pp. 1-84, 2019.

[27] M. E. Porter, "Essay," Scientific American, vol. 264, no. 4, 1991.

[28] J. Barney, "Firm resources and sustained competitive advantage," Journal of Management, vol. 17, no. 1, pp. 99-120, 1991.

[29] K. Mårtensson and K. Westerberg, "Corporate environmental strategies towards sustainable development," Business Strategy and the Environment, vol. 25, pp. 1-9, 2016.

[30] K. Rennings, "Redefining innovation - eco-innovation research and the contribution from ecological economics," Ecological Economics, vol. 32, no. 2, pp. 319-332, 2000.

[31] J. Ammenberg and O. Hjelm, "Tracing business and environmental effects of environmental management systems?a study of networking small and medium-sized enterprises using a joint environmental management system," Business Strategy and the Environment, vol. 12, no. 3, pp. 163-174, 2003.

[32] H. Cao and Z. Chen, "The driving effect of internal and external environment on green innovation strategy-The moderating role of top management's environmental awareness," Nankai Business Review International, vol. 10, no. 3, pp. 342-361, 2019.

[33] J. J. Wang, J. Xu, and J. He, "Spatial impacts of high-speed railways in China: a total-travel-time approach," Environment \& Planning A, vol. 45, no. 9, pp. 2261-2280, 2013.

[34] B. Guirao, J. L. Campa, and N. S. Casado, "Labour mobility between cities and metropolitan integration: the role of high speed rail commuting in Spain," Cities, vol. 78, pp. 140-154, 2018.

[35] F. Montobbio and V. Sterzi, "The globalization of technology in emerging markets: a gravity model on the determinants of international patent collaborations," World Development, vol. 44, pp. 281-299, 2013.

[36] P. M. Romer, "Increasing returns and long-run growth," Journal of Political Economy, vol. 94, no. 5, pp. 1002-1037, 1986. 
[37] P. Aghion and P. Howitt, "Capital, innovation, and growth accounting," Oxford Review of Economic Policy, vol. 23, no. 1, pp. 79-93, 2007.

[38] B. Crepon, E. Duguet, and J. Mairessec, "Research, innovation and pty: an econometric analysis at the firm level," Economics of Innovation and New Technology, vol. 7, no. 2, pp. 115-158, 1998.

[39] S. Bernstein, X. Giroud, and R. R. Townsend, "The impact of venture capital monitoring," The Journal of Finance, vol. 71, no. 4, pp. 1591-1622, 2016.

[40] M. Fritsch and D. Schilder, "Does venture capital investment really require spatial proximity an empirical investigation," Environment \& Planning A, vol. 40, no. 9, pp. 2114-2131, 2008.

[41] B. Klagge and R. Martin, "Decentralized versus centralized financial systems: is there a case for local capital markets?" Journal of Economic Geography, vol. 5, no. 4, pp. 387-421, 2005.

[42] A. Doran and G. Bannock, "Publicly sponsored regional venture capital: what can the UK learn from the US experience?" Venture Capital, vol. 2, no. 4, pp. 255-285, 2000.

[43] C. M. Mason and R. T. Harrison, "The geography of venture capital investments in the UK," Transactions of the Institute of British Geographers, vol. 27, no. 4, pp. 427-451, 2002.

[44] D. Kong, L. Liu, and S. Liu, "Market information traveling on high-speed rails: the case of analyst forecasts," Pacific-Basin Finance Journal, vol. 61, Article ID 101320, 2020.

[45] C. Kuang, Z. Liu, and W. Zhu, "Need for speed: high-speed rail and firm performance," SSRN Electronic Journal, vol. 66, no. 1, Article ID 101830, 2020.

[46] M. Fritsch and V. Slavtchev, "Determinants of the efficiency of regional innovation systems," Regional Studies, vol. 45, no. 7, pp. 905-918, 2011.

[47] G. M. Grossman and E. Helpman, "Endogenous innovation in the theory of growth," The Journal of Economic Perspectives, vol. 8, no. 1, pp. 23-44, 1994.

[48] F. Moshirian, X. Tian, B. Zhang, and W. Zhang, "Stock market liberalization and innovation," Journal of Financial Economics, vol. 139, no. 3, pp. 985-1014, 2021.

[49] X. Yang, H. Zhang, S. Lin, J. Zhang, and J. Zeng, "Does highspeed railway promote regional innovation growth or innovation convergence?" Technology in Society, vol. 64, Article ID 101472, 2021.

[50] P. Zhang, Y. Zhao, X. Zhu, Z. Cai, J. Xu, and S. Shi, "Spatial structure of urban agglomeration under the impact of highspeed railway construction: based on the social network analysis," Sustainable Cities and Society, vol. 62, Article ID 102404, 2020.

[51] J. C. Delgado, J. A. C. Aragón, N. O. D. Mandojana, and A. R. Manzanares, "The effect of internal barriers on the connection between stakeholder integration and proactive environmental strategies," Journal of Business Ethics, vol. 107, no. 3, pp. 281-293, 2012.

[52] A. Verbeke and K. Buysse, "Proactive environmental strategies: astakeholder management perspective," Strategic Management Journal, vol. 24, pp. 453-470, 2003.

[53] Y. S. Chen, C. H. Chang, and F. S. Wu, "Origins of green innovations: the differences between proactive and reactive green innovations," Management Decision, vol. 50, no. 3, pp. 368-398, 2012.

[54] I. Ketata, W. Sofka, and C. Grimpe, "The role of internal capabilities and firms' environment for sustainable innovation: evidence for Germany," $R$ \& $D$ Management, vol. 45, no. 1, pp. 60-75, 2015.
[55] J. A. Ford, J. Steen, and M. Verreynne, "How environmental regulations affect innovation in the Australian oil and gas industry: going beyond the Porter Hypothesis," Journal of Cleaner Production, vol. 84, pp. 204-213, 2014.

[56] H. Lin, S. X. Zeng, H. Y. Ma, G. Y. Qi, and V. W. Y. Tam, "Can political capital drive corporate green innovation? Lessons from China," Journal of Cleaner Production, vol. 64, pp. 63-72, 2014.

[57] Y. Huang and Y. Wang, "How does high-speed railway affect green innovation efficiency? A perspective of innovation factor mobility," Journal of Cleaner Production, vol. 265, Article ID 121623, 2020.

[58] K. J. Arrow, "Economic welfare and the allocation of resources for invention," in The Rate and Direction of Inventive Activity, pp. 609-626, Princeton University Press, Princeton, NJ, USA, 1962.

[59] U. Kaiser, H. C. Kongsted, and T. Rønde, "Does the mobility of R\&D labor increase innovation?" Journal of Economic Behavior \& Organization, vol. 110, pp. 91-105, 2015.

[60] A. Breitenfellner, J. C. Cuaresma, P. Mooslechner, and D. G. Ritzberger, "The impact of EU enlargement in 2004 and 2007 on FDI and migration flows-gravity analysis of factor mobility," Monet. Policy Econ, vol. 28, pp. 101-120, 2008.

[61] J. M. C. S. Silva and S. Tenreyro, "The log of gravity," The Review of Economics and Statistics, vol. 88, no. 4, pp. 641-658, 2006.

[62] M. Ma, W. Cai, W. Cai, and L. Dong, "Whether carbon intensity in the commercial building sector decouples from economic development in the service industry? Empirical evidence from the top five urban agglomerations in China," Journal of Cleaner Production, vol. 222, pp. 193-205, 2019.

[63] Ministry of Transport of the People's Republic of China, 2020, "2020 transportation industry development statistics bulletin,” http://www.gov.cn/xinwen/2021-05/19/content_ 5608523.htm.

[64] W. Xu and Y. Huang, "The correlation between HSR construction and economic development - empirical study of Chinese cities," Transportation Research Part A: Policy and Practice, vol. 126, pp. 24-36, 2019.

[65] Uic, "A comprehensive system allowing door-to-door transportation," 2021, https://uic.org/passenger/highspeed/.

[66] Z. J. Acs, L. Anselin, and A. Varga, "Patents and innovation counts as measures of regional production of new knowledge," Research Policy, vol. 31, no. 7, pp. 1069-1085, 2002.

[67] K. Du, P. Li, and Z. Yan, "Do green technology innovations contribute to carbon dioxide emission reduction? Empirical evidence from patent data," Technological Forecasting and Social Change, vol. 146, pp. 297-303, 2019.

[68] H.-N. Su and I. M. Moaniba, "Does innovation respond to climate change? Empirical evidence from patents and greenhouse gas emissions," Technological Forecasting and Social Change, vol. 122, pp. 49-62, 2017.

[69] M. Yi, X. Fang, L. Wen, F. Guang, and Y. Zhang, "The heterogeneous effects of different environmental policy instruments on green technology innovation," International Journal of Environmental Research and Public Health, vol. 16, pp. 1-19, 2019.

[70] M. S. Ullah, “Determinants of international labor migration from Bangladesh: a gravity model of panel data," 社会シス テム研究, vol. 25, pp. 125-146, 2012.

[71] G. J. Borjas, "SELF-SELECTION and the earnings OF immigrants," Tetrahedron Letters, vol. 28, pp. 2383-2386, 1987.

[72] D. Karemera, V. I. Oguledo, and B. Davis, "A gravity model analysis of international migration to North America," Applied Economics, vol. 32, no. 13, pp. 1745-1755, 2000. 
[73] R. Cervero and $\mathrm{K}$. Wu, "Polycentrism, commuting, and residential location in the San Francisco Bay area," Environment \& Planning A, vol. 29, no. 5, pp. 865-886, 1997.

[74] J. Hunt, "Staunching emigration from east Germany: age and the determinants of migration," Journal of the European Economic Association, vol. 4, no. 5, pp. 1014-1037, 2006.

[75] K. S. So, P. F. Orazem, and D. M. Otto, "The effects of housing prices, wages, and commuting time on joint residential and job location choices," American Journal of Agricultural Economics, vol. 83, no. 4, pp. 1036-1048, 2001.

[76] J. J. Lewer and H. V. D. Berg, "A gravity model of immigration," Economics Letters, vol. 99, no. 1, pp. 164-167, 2008.

[77] K. M. Murphy, A. Shleifer, and R. W. Vishny, "The allocation of talent: implications for growth," Quarterly Journal of Economics, vol. 106, no. 2, 1991.

[78] L. V. Bertalanffy, General Systems Theory: Foundations, Developments, Applications, George Braziller, Inc., NY, US, 1968.

[79] R. Chami, C. Fullenkamp, and S. Jahjah, "Are immigrant remittance flows a source of capital for development," IMF Staff Papers, vol. 52, pp. 55-81, 2005.

[80] R. Portes, H. Rey, and Y. Oh, "Information and capital flows: the determinants of transactions in financial assets," European Economic Review, vol. 45, no. 4-6, pp. 783-796, 2001.

[81] X. Zhang, W. Wu, Z. Zhou, and L. Yuan, "Geographic proximity, information flows and corporate innovation: evidence from the high-speed rail construction in China," Pacific-Basin Finance Journal, vol. 61, Article ID 101342, 2020.

[82] S. Zheng and M. E. Kahn, "China's bullet trains facilitate market integration and mitigate the cost of megacity growth," Proceedings of the National Academy of Sciences of the United States of America, vol. 110, pp. 1248-1253, 2013.

[83] P. Moser and A. Voena, "Compulsory licensing: evidence from the trading with the enemy act," The American Economic Review, vol. 102, no. 1, pp. 396-427, 2012.

[84] Q. Kong, C. Shen, R. Li, and Z. Wong, "High-speed railway opening and urban green productivity in the post-COVID19: evidence from green finance," Global Finance Journal, vol. 49, Article ID 100645, 2021.

[85] R. M. Baron and D. A. Kenny, "The moderator-mediator variable distinction in social psychological research: c," Journal of Personality and Social Psychology, vol. 51, no. 6, pp. 1173-1182, 1986.

[86] M. Mani and D. Wheeler, "In search of pollution havens? Dirty industry in the world economy, 1960 to 1995," The Journal of Environment \& Development, vol. 7, no. 3, 1998.

[87] I. Walter and J. L. Ugelow, "Environmental policies in developing countries," Ambio, vol. 8, pp. 102-109, 1979.

[88] C. Fang and D. Yu, "Urban agglomeration: an evolving concept of an emerging phenomenon," Landscape and Urban Planning, vol. 162, pp. 126-136, 2017.

[89] Q. Ma, T. Zhang, and J. Li, "Estimate on spillover effect of environmental pollution between peripheral areas," Chinese Journal of Population Resources and Environment, vol. 17, no. 3, pp. 254-266, 2019.

[90] Ministry of Railways of the People's Republic of China, "The medium and long-term railway network plan,” 2016, http:// www.nra.gov.cn/jgzf/flfg/gfxwj/zt/other/201607/t20160721_ 26055.shtml.

[91] J. Sun, Z. Wang, and Q. Zhu, "Analysis of resource allocation and environmental performance in China's three major urban agglomerations," Environmental Science and Pollution Research, vol. 27, no. 27, Article ID 34299, 2020.
[92] Y. Sheng, J. Zhao, X. Zhang, J. Song, and Y. Miao, "Innovation efficiency and spatial spillover in urban agglomerations: a case of the beijing-th," Growth and Change, vol. 50, no. 4, pp. 1280-1310, 2019.

[93] M. Diao, "Does growth follow the rail? The potential impact of high-speed rail on the economic geography of China," Transportation Research Part A: Policy and Practice, vol. 113, pp. 279-290, 2018.

[94] J. Hao, P. Zhang, Y. Wei, and X. Mou, "Causes of spatial patterns of livability in Chinese cities: MGWRL analysis based on Didi's big data," Working paper of Didi Development Research Institute, China Development Research Institute of Shanghai Jiao Tong University, Shanghai, China, Article ID 4021025, 2019.

[95] H. Xu, X. Feng, Y. Chen, and M. Lu, "Towards an efficient and livable city: Didi "Urban Development Index," Working paper of Didi Development Research Institute, China Development Research Institute of Shanghai Jiao Tong University, Shanghai, China, 2019.

[96] G. Michaels, "The effect of trade on the demand for skill: evidence from the interstate highway system," The Review of Economics and Statistics, vol. 90, no. 4, pp. 683-701, 2008.

[97] G. Duranton and M. A. Turner, "Urban growth and transportation," The Review of Economic Studies, vol. 79, no. 4, pp. 1407-1440, 2012.

[98] G. Duranton and M. A. Turner, "The fundamental law of road congestion: evidence from US cities," The American Economic Review, vol. 101, no. 6, pp. 2616-2652, 2011.

[99] N. Baum-Snow, L. Brandt, J. V. Henderson, M. A. Turner, and Q. Zhang, "Roads, railroads, and decentralization of Chinese cities," The Review of Economics and Statistics, vol. 99, no. 3, pp. 435-448, 2017.

[100] E. Duflo and R. Pande, "Dams," Quarterly Journal of Economics, vol. 122, no. 2, pp. 601-646, 2007.

[101] C. F. Baum, M. E. Schaffer, and S. Stillman, "Enhanced routines for instrumental variables/generalized method of moments estimation and testing," STATA Journal: Promoting communications on statistics and Stata, vol. 7, no. 4, pp. 465-506, 2007.

[102] J. H. Stock and M. Yogo, "Testing for weak instruments in Linear Iv regression," Identification and Inference for Econometric Models, Cambridge University Press, NY, USA, pp. 80-108, 2005.

[103] D. Staiger and J. H. Stock, "Instrumental variables regression with weak instruments," Econometrica, vol. 65, no. 3, p. 557, 1997.

[104] H. Wang, T. Guo, and Q. Tang, "The effect of national culture on corporate green proactivity," Journal of Business Research, vol. 131, pp. 140-150, 2021.

[105] M. Dell, B. F. Jones, and B. A. Olken, "Temperature shocks and economic growth: evidence from the last half century," American Economic Journal: Macroeconomics, vol. 4, no. 3, pp. 66-95, 2012.

[106] X. Cai, Y. Lu, and J. Wang, "The impact of temperature on manufacturing worker productivity: evidence from personnel data," Journal of Comparative Economics, vol. 46, no. 4, pp. 889-905, 2018.

[107] S. D. Galloway and R. J. Maughan, "Effects of ambient temperature on the capacity to perform prolonged cycle exercise in man," Medicine \& Science in Sports \& Exercise, vol. 29, pp. 1240-9, 1997.

[108] O. Deschênes and M. Greenstone, "Climate change, mortality, and adaptation: evidence from annual fluctuations in weather in the US," American Economic Journal: Applied Economics, vol. 3, pp. 152-185, 2011. 